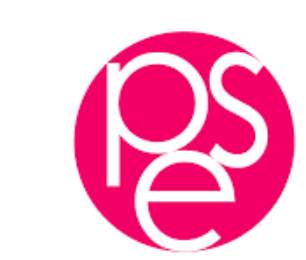

PARISSCHOOLOFECONOMICS
ECOLED'ECONOMIE DE PARIS

WORKING PAPER N 2019 - 27

Technology-induced Trade Shocks? Evidence from Broadband Expansion in France

Clément Malgouyres

Thierry Mayer

Clément Mazet-Sonilhac

JEL Codes:

Keywords : 


\title{
Technology-induced Trade Shocks? Evidence from Broadband Expansion in France*
}

\author{
Clément Malgouyres ${ }^{\dagger} \quad$ Thierry Mayer ${ }^{\ddagger}$ \\ Clément Mazet-Sonilhac ${ }^{\S}$
}

June 12, 2019

\begin{abstract}
In this paper, we document the presence of "technology-induced" trade in France between 1997 and 2007 and assess its impact on consumer welfare. We use the staggered roll-out of broadband internet to estimate its causal effect on the importing behavior of affected firms. Using an event-study design, we find that broadband expansion increases firm-level imports by around $25 \%$. We further find that the "sub-extensive" margin (number of products and sourcing countries per firm) is the main channel of adjustment and that the effect is larger for capital goods. Finally, we develop a model where firms optimize over their import strategy and which yields a sufficient statistics formula for the quantification of the effects of broadband on consumer welfare. Interpreted within this model, our reduced-form estimates imply that broadband internet reduced the consumer price index by $1.7 \%$ and that the import-channel, i.e. the enhanced access to foreign goods that is allowed by broadband, accounts for a quarter of that effect.
\end{abstract}

\footnotetext{
${ }^{*}$ We are grateful to Philippe Aghion, Antonin Bergeaud, Antoine Bozio, Thomas Breda, Bruno Crépon, François Fontaine, Tarek Harchaoui, Claire Lelarge, David Margolis, Isabelle Méjean, Jean-Stéphane Mésonnier, Ariell Reshef, Frédérique Savignac, Marcel Timmer and participants at Crest, Collège de France, Groningen GEM, 2018 European meeting of the Econometric Society in Naples, the 2018 DARES conference, PSE labour seminar, Bolzano OECD-workshop, RES 2019, OECD applied economics seminar and the $9^{\text {th }}$ meeting of the Urban Economics Association in Amsterdam. This work is supported by public grants overseen by the French National Research Agency (ANR) as part of the "Investissements d'avenir" program within the frameworks of the Centre d'accès sécurisé aux données - CASD (ANR-10-EQPX-17). We thank Julienne Liang for help with understanding the data on local exchange upgrading dates. We are extremely grateful to Laurian Choain and ARCEP for providing the ARCEP data on local exchanges coverage. Researchers from the Banque de France participated in this work, the views expressed in this paper are their own and do not necessarily reflect those of the Banque de France or the Eurosystem.

${ }^{\dagger}$ Institut des Politiques Publiques (IPP) and Paris School of Economics (PSE)

${ }^{\ddagger}$ Sciences Po, Banque de France, CEPII and CEPR

${ }^{\S}$ Sciences Po, Banque de France
} 


\section{Introduction}

From 1995 to 2008, the value of imports by high-income countries has grown twice as fast as global GDP. ${ }^{1}$ This acceleration of globalization has induced welldocumented labor market impacts (Autor et al., 2016b, summarize the recent literature on the impact of the "China shock" on labor market outcomes), as well as rises in consumer welfare through lower prices and gains in varieties (see Feenstra and Weinstein, 2017, for a recent example). This period was also characterized by radical innovations in information and communication technologies (ICT) and by their rapid diffusion throughout the world economy. It is most likely that the "ICT revolution" (Cohen et al., 2004) lowered the cost of carrying out international transactions and contributed to raising the pace of economic integration. To the extent that ICT facilitated international trade, part of the consumer gains induced by trade development should be attributed to the diffusion of ICTs. In this paper, we test this proposition by estimating the effect of the diffusion of broadband internet on the importing behavior of French firms from 1997 to 2007 and by developing a theoretical framework to assess the impact of broadband-induced imports on consumer welfare.

Identifying the causal effect of technology on trade is generically difficult because of its endogeneity. The French data and context allow us to make progress on the causal identification of how technology affects firm-level import behavior. In terms of data, we assemble a novel dataset on broadband internet availability at the municipality level over the 1997-2007 period and combine it with information regarding firms' importing behavior. Regarding the context, we exploit the gradual roll-out of broadband internet in France, which was staggered over several years due to limited funding and completed primarily in order to maximize population coverage with only limited attention paid to local economic conditions. This setup provides natural ground for an event-study identifying how ICT availability affected firms' importing behavior.

We find that the local access to broadband internet leads to a surge in the total value of firm-level imports. Our point estimate implies a $25 \%$ increase after five years. When applied to our estimating sample and taking into account dynamic effects, the aggregate effect of broadband expansion on the value of imports in constant dollars over the 1997-2007 period was to increase its growth rate from $75 \%$ to $91 \%$, i.e. 16 p.p. or $21 \%$. Our results are robust to several potential threats

\footnotetext{
${ }^{1}$ The World Bank World Development Indicators report that the ratio of imports over GDP for high-income countries has grown from $43 \%$ to $61 \%$.
} 
to identification. First, we find no evidence of pre-expansion differential trends in outcomes. Second, while it is possible that broadband introduction was systematically associated with contemporaneous local economic shocks, we show that adding a rich set of city-level controls for local industry and income dynamics hardly affects our estimates. Additionally, flexibly controlling for changes in local labor market conditions, by including a large set of local fixed effects interacted with year dummies, barely changes our estimates.

We further document changes in importing activities along several margins. We find that the increase in the overall value of imports is primarily associated with an increase in the number of flows and find no effect on the average value per flow (where a flow is defined as the combination of an importing firm, an origin country and a specific product). All types of goods (intermediary, consumption and capital) are affected. We also find that broadband internet has a positive impact on firm performance as measured by value-added and sales. Importantly, the import-intensity of firms increases: the ratio of imports over sales is positively affected and the share of domestic inputs in overall consumption of intermediates declines.

In the final part of the paper, we assess the welfare implications of our empirical findings through the lens of a simple but general theoretical model of firm-level imports. We use the standard monopolistic competition cum CES demand setup for final goods so as to link firm-level sales with (quality-adjusted) unit cost. On the production side, firms combine labor with domestic and imported inputs. Our model features the sufficiency result highlighted by Blaum et al. (2018): the firm-level domestic share of inputs fully characterizes the contribution of imports of intermediates to the reduction of its unit cost. The generality of the setup allows us to remain agnostic regarding which type of trade costs (variable, fixed per destination or product, search friction etc.) is affected by the broadband internet expansion shock. It also generates a very parsimonious framework for welfare analysis. The overall effect of access to fast internet on the consumer price index and the contribution of enhanced access to foreign inputs to that overall effect (which we refer to as the import channel) are expressed as a function of two reduced-form estimates and three parameters to be calibrated (either from descriptive statistics or from the existing relevant literature). Under our preferred values for calibrated parameters, our event-study estimates imply that broadband internet led to a price index decrease of $1.7 \%$. The import channel contributed up to $0.48 \%$, i.e. about one quarter of the overall effect. 
The remainder of the paper is structured as follows. We start by relating our paper to several streams of papers that have studied the links between technology improvements and trade. We then present the data and institutional context in Section 3. We detail our empirical approach in Section 4. Baseline results and robustness checks are presented in Section 5. Section 6 analyses the heterogeneity of the effect by types of goods and sourcing country. The section additionally presents findings on firm sales and value-added as well as import intensity (imports over sales and imports over overall intermediate consumption) that will be important inputs into the welfare analysis that is carried out in Section 7. In Section 7, we introduce a firm-level model of input importing and derive the welfare formula allowing us to quantify the contribution of the import-channel as well as the total effect of broadband internet on consumer welfare.

\section{Literature}

This paper connects with several strands of the literature. First, it enriches the large literature regarding the interactions between trade and technical change. Second, it has implications for the origins of trade shocks whose effects have been extensively studied in recent years. Finally, it contributes to the literature on firm international sourcing choices.

While technology is often mentioned as a force amplifying globalization, empirical evidence on the matter appears scarce. For instance, in his rich account of the recent wave of globalization and its interplay with technology, Muendler (2017) mentions the possibility of technology-induced trade but does not cite empirical papers estimating the impact of ICTs on trade flows. Baldwin (2016) argues that globalization over the 1990s and 2000s was driven by information technology by lowering the cost of coordinating activities across borders. It boosted intra-industry trade between advanced economies and a handful of emerging economies as multinational firms from the North moved labor-intensive tasks to the South. Steinwender (2018) provides empirical evidence on the role of the ancestor of modern ICT on trade during the 1800s by studying the impact of the telegraph on trade between the United Kingdom and the United States. A possible reason as to why modern data causal evidence on technology-induced trade is rather scarce might be related to the difficulty of measuring technology availability at the firm-level that varies over time while simultaneously observing trade patterns. Consequently, most studies documenting a positive impact of ICT on 
trade are either at the country (Portugal-Perez and Wilson, 2012; Clarke and Wallsten, 2006) or macro-regional level (Barbero and Rodriguez-Crespo, 2018). ${ }^{2}$

There are some recent exceptions that have documented the effect of technology using firm-level trade and outsourcing decisions. Kneller and Timmis (2016) find a positive effect of broadband internet on the export of services. Fort (2017) documents the firm-level relationship between investing in an electronicintegrated network and outsourcing, either domestic or international, of complex manufacturing tasks. In the context of developing African economies and relying on survey data, Hjort and Poulsen (2018) show that fast internet increases employment and that rising exports is one of the mechanisms explaining the upward shift in labor demand. Most closely related to our paper is Akerman et al. (2018) who estimate how broadband local availability affects the effect of distance on trade flows using a panel of bilateral trade flows between Norwegian cities and foreign countries, building on the identification strategy of Akerman et al. (2015). While their results display a significant interaction effect between fast internet and distance, they do not find that broadband increases significantly trade flows. Their coefficients are positive, although imprecisely estimated. We depart from these papers in several ways. First, we focus on the import side with the aim of quantifying the welfare consequences of the broadband-induced variation in imports. Second, we are able to document additional margins of adjustment of trade to broadband expansion, notably the "sub-extensive" margin of imports (i.e. the number of goods and origin-country imported by firms) that has been shown to be relevant in other settings (Gopinath and Neiman, 2014). Third, while Akerman et al. (2018) frame their empirical analysis in the gravity literature, aiming at explaining the distance puzzle, we adopt a more agnostic approach and aim primarily at documenting the extent to which technology-induced trade might have contributed to the recent rise in import penetration across advanced economies. Finally, we combine our estimates with a simple theoretical framework to quantify the impact of broadband internet on consumer welfare, relying on a sufficient statistic approach. We focus on welfare and do not model explicitly the impact of internet on the geography of trade. ${ }^{3}$ A limitation of our paper with respect

\footnotetext{
${ }^{2}$ Several papers have recently documented the impact of trade on innovation, i.e. the reverse direction of causality compared to our focus. Aghion et al. (2018) find that expanding exporting opportunities increase the innovative activities of the most productive firms. On the import side, Bloom et al. (2016) find that greater Chinese import competition from China is associated with higher firm patenting in a panel of European firms while Autor et al. (2016a) find opposite results in the US case.

${ }^{3}$ Note also that our sample size is considerably larger due to the sheer number of municipalities in France (about 35,000 cities versus 400 in Norway) thus allowing us to uncover effects that might be otherwise impossible to detect.
} 
to Akerman et al. (2018) is that we do not observe firm-level adoption and therefore focus on local availability while they have access to information on broadband adoption from surveys. They can therefore estimate the effect of adoption on trade while we focus on the reduced-form. Note however that the reduced-form effect is relevant policy-wise as it is straightforward to increase local broadband availability through policy intervention while manipulating adoption involves more intricate interventions. ${ }^{4}$

Starting with Autor et al. (2013), a growing body of evidence, based on a local labor market approach ${ }^{5}$, has documented the impact of trade shocks from emerging countries - in particular China and Eastern European countries, see Dauth et al. (2014) - on the local labor market outcomes (manufacturing employment, wages or employment rate etc.). Most studies analyze the effect of trade or technology in isolation, treating the factor left-out as a potential omitted variable to account for. By contrast, Autor et al. (2015) attempt to "untangle" the respective effect of trade and technology on several local labor market outcomes, notably the decline in manufacturing employment in the USA. Their analysis, however, considers sectoral aggregate trade flows as given. We instead make the point that the remarkable increase in trade flows over the period is in part driven by concomitant technical change. Moreover, we also find a large effect for imports sourced from Eastern European countries and China, suggesting that the recent "trade shocks" from the 2000s were, in part, driven by technological change. Our results echo the point raised by Fort et al . (2018) that in the presence of technologyinduced trade, it is delicate to disentangle the effects of technology from those of trade.

A sizable reduced-form literature has documented that increased access to foreign inputs lead to favorable firm-level outcomes, notably productivity gains (Amiti and Konings, 2007; Topalova and Khandelwal, 2011). Most of the literature relies on trade liberalization episode to estimate the effect of trade in inputs on firm-level outcomes. ${ }^{6}$ We contribute to this literature by using a new source of identifying variation (staggered roll-out of an ICT) and implementing a transpar-

\footnotetext{
${ }^{4}$ See Andrews et al. (2018) for a cross-country empirical investigation of the numerous determinants of ICT adoption by firms and their complex interaction.

${ }^{5}$ This approach was pioneered by Topalova (2010) and Kovak (2013) who analyse the local impact of trade liberalization in India and Brazil respectively.

${ }^{6}$ In their recent assessment of the literature Shu and Steinwender (2019) review 20 papers, 15 of which adopt a reduced-form approach. Among these 15 papers, 14 rely on variation in foreign input access driven by trade policy reforms. The one exception is Juhász and Steinwender (2018) who estimate the effect of the roll-out of the telegraph network on technology adoption. While the source of variation is similar to ours, the context (19th century), the level of variation (crosscountry) and the outcome differ starkly from our set-up.
} 
ent event-study design that is allowed by the longitudinal nature of the data and the large number of local events. An additional contribution is to build on recent theoretical results in the literature on firm-level importing (Blaum et al., 2018) in order to translate our reduced-form estimates overall impact of broadband internet consumer welfare and to isolate the contribution of the import channel.

As such, our findings also relate to the theoretical and structural literature studying the link between international sourcing, productivity and consumer welfare (Halpern et al., 2015). As broadband internet is found to increase the share of spending on foreign inputs as well as the variety of inputs, trade appears to be one of the mechanisms through which fast internet boosted productivity and ultimately consumer welfare. The paper documents the direct effect of broadband on firm-level outcomes, most importantly sales and value-added (subsection 6.3). In order to quantify the import channel through which fast internet boosts imports, we take our reduced-form estimates into a general model of firm-level importing. Rather than specifying the model fully and estimating its parameters (as in e.g. Sandoz, 2017; Antras et al., 2017), we rely instead on a sufficient statistics approach (Chetty, 2009) as first developed by Blaum et al. (2018) in the import literature. ${ }^{7}$ Our estimates combined with the calibration of this model with French data implies that broadband internet allowed for a reduction of about $1.7 \%$ in the unit cost of production and that about $25 \%$ of that overall effect is related to the import channel. ${ }^{8}$

\section{Data and context}

\subsection{Context: the diffusion of Broadband Internet in France}

The ADSL technology. The ADSL (Asymmetric Digital Subscriber Line) is a data communication technology that enables fast data transmission over copper telephone lines (much faster than what a conventional voiceband modem could pro-

\footnotetext{
${ }^{7}$ These micro-results build on the seminal work of Arkolakis et al. (2012) that show that in a large class of trade models observed changes in the share of domestic consumption, together with the price elasticity of trade are sufficient statistics for evaluating welfare changes associated with a foreign shock.

${ }^{8}$ Perhaps more incidentally, our paper contributes to the literature on the overall impact of broadband internet (Bertschek et al., 2015) for a recent review. Few papers documented the local economic impact of broadband internet in France and no paper we are aware of look at firm-level outcomes. In a set of two papers, Houngbonon and Liang document a negative effect of broadband penetration, as measured by ratio of residential connections to the number of households, on the local Gini coefficient over the 2009-2013 period (Houngbonon and Liang, 2017) and a positive effect on service employment (Houngbonon and Liang, 2018). We instead focus on the period of expansion of broadband availability that is driven by the gradual upgrading of the copper wire infrastructure over the 1999 to 2007 period.
} 
vide). In the ADSL technology, bandwidth and bit rate are said to be asymmetric, meaning greater towards the customer premises (downstream) than the reverse (upstream). Eligibility for ADSL depends on the distance between the final customer (e.g. home or office) and the Local Exchange (LEs), since the intensity and the quality of the analog signal decreases as it is routed over the copper lines. Local Exchanges are the telephone exchanges owned by the incumbent operator France Télécom (later renamed Orange) into which subscribers' telephone lines end. As of 2008, there were about 17000 LEs spread throughout the country. Initially dedicated to the telephone network, LEs are essential for Internet users who subscribe to ADSL. LEs aggregate local traffic and then direct it via the socalled backbone (i.e. higher levels of the network) towards the world wide web. A key feature of the ADSL technology is that one can supply high-speed Internet by upgrading the LE while relying on the existing (copper) local loop to connect the premises of the final customers. The upgrading involves the installation of an equipment inside the LE called a DSLAM (Digital subscriber line access multiplexer) that is required in order to recover the data transmitted via ADSL on the local copper loop and adapt it so it can be transmitted to the higher levels of the network (which are typically relying on optical fiber). The upgrading of local LEs is the key source of variation we will use in our empirical analysis (see section 3.2.1 for more details on the data).

The ADSL roll-out in France. The ADSL technology became popular during the 1990s, as many OECD countries were planning the expansion of services related to information and communications technology. In the early 2000s in France, the deployment of the technology beyond France's largest cities was slow. The causes for this staggered deployment are multiple. First, France Telecom (FT), the monopolistic telecom supplier at the time and still the main supplier today, was unsure as to whether it was going to be able to make the upgraded infrastructure available to new competitors with a positive markup or not. The uncertainty regarding the wholesale price FT was going to be able to charge made the firm reluctant to upgrade LEs beyond the largest cities (see Sénat, 2002, p.232). This uncertainty was lifted after a series of decisions by the regulatory agency set the conditions of that wholesale market (Arcep, 2002).

Moreover, at the same time France Telecom had to invest massively in upgrading its LEs to ADSL, it went through an debt crisis which ended with what was essentially a government bailout in 2002. One can find anecdotal evidence of the impatience of the French government in accounts of Parliamentary debate (at 
the Senate) regarding the excessively slow expansion of broadband internet (Tregouet, 2001) and the difficult cooperation between the French government (the Ministry in charge of the Industry) and France Télécom.

Under the impulse of the government - which increased its stake in the firm during the 2002 bailout of the firm - France Telecom pledged in 2003 to cover $90 \%$ of the French (metropolitan) population by the end of 2005, i.e. all local exchanges (LEs) with more than 1000 lines, for a total investment of $600 \mathrm{M}$ euros (750 M euros in 2018 prices) (Telecom, 2003).

Between 2004 and 2007, local governments (called départements ${ }^{9}$ ) started to play a role in subsidizing deployment and favoring competition among providers. Most relevant for broadband expansion is the creation of a contract between local governments the "Plan Département Innovant". It is a contract whereby France Telecom pledged to equip all LEs with more than 100 connections within a year in that département. The proclaimed target of the plan was to raise the French population coverage up to $96 \%$ by the end of 2005 and activate all the remaining LE by the end of 2006 (Telecom, 2003). About 50 departments signed the chart in 2004 even though many experienced delays. This commercial initiative was widely perceived as a way for FT to counter the direct involvement of départements in broadband provision that was made possible by a law voted in $2004 .{ }^{10}$ We account for the role of départements in our empirical analysis by carrying a withindépartement analysis (we include département-year fixed effects throughout). FT claimed to have reached the full coverage of all relevant LEs in July 2007 (Le Gall, 2007), covering $98 \%$ of the French metropolitan population.

Overall, the account of the broadband expansion in France over the period suggests that it was gradual due to uncertainty regarding the capacity of France Telecom to undergo the investment until 2002. After 2002, with the strong impulse of the government, France Telecom started covering more secondary areas with a focus on the overall number of lines per LE with only limited attention paid to local economic potential. While accelerated, the coverage remained gradual due to operational limits on the part of FT and took about 2 more years than anticipated in 2003.

Our main effects of interest are identified out of the gradual diffusion of the new technology in different LEs over space and time. The question of what were the criteria for deciding to "treat" one LE before another is of course central for our paper. It is the topic of a whole section immediately preceding the results

\footnotetext{
${ }^{9}$ There 95 départements in mainland France.

${ }^{10} \mathrm{LOI}$ n 2004-575 du 21 juin 2004 pour la confiance dans l'économie numérique
} 
(section 4.2), where we present evidence that the main determinant was the citylevel population density, with no role for levels or trends in the trade patterns of the city.

Finally, it is worth noting that several sources show that the ADSL technology, while progressively replaced by other technologies - notably direct access to the optic fiber or FTTO (fiber to the office) -, is still the main way firms access the internet. In particular, based on a recent survey, it appears that $73 \%$ of SMEs use ADSL technology only as of 2016 (Arcep, 2016). Moreover it constituted not only a massive improvement in terms of speed (from 56 to $512 \mathrm{kbit} / \mathrm{s}$ for a transition from a classical to first generation ADSL connection) but also in terms of cost and time of connection. ${ }^{11}$

\subsection{Data}

In this paper, we combine three main sources of information: a unique city-level dataset on broadband internet availability, firm-level trade and employment, and firm-level balance sheet information. We provide a detailed description of our data in the following subsections. More details on the datasets used is provided in Appendix B.1.

\subsubsection{Broadband internet data}

The most novel aspect of our data is the (manually collected) date of upgrade to ADSL in mainland France for each Local Exchange (LE)'s. ${ }^{12}$ The historical operator was compelled by law to make this data available to other operators as well as websites allowing consumers to gauge the quality of their line. The data was collected through one such website. ${ }^{13}$ We additionally obtained data from the regulatory agency (ARCEP) regarding the geographical coverage of each LE. The data documents the area of each census block (IRIS) that is covered by a given LE. Each city in France is partitioned into census-blocks.

Combining both datasets, we construct a continuous measure of broadband access of city $i$ at year $t$. This measure, which we denote $\widetilde{Z}_{i t}$, is a time-weighted

\footnotetext{
${ }^{11} \mathrm{FT}$ was providing services at $128 \mathrm{kbits}$ at a much higher cost (Badré, 2007).

${ }^{12}$ Throughout the paper, broadband or ADSL refers to first generation ADSL that is associated with speed of $512 \mathrm{kbit} / \mathrm{s}$.

${ }^{13}$ We were able to check with economists at Orange that our dates matched exactly their data for the years within the sample (1999-2007).
} 
percentage of area covered in city $i$. It is formally defined as:

$$
\widetilde{Z}_{i t}=\sum_{b \in i} \underbrace{\frac{\# \text { days with access in } b \text { since Jan } 1 \text { st of } t}{\# \text { days in year } t}}_{=D_{b t}} \times \underbrace{\frac{\text { area }_{b t}}{\sum_{b \in i} \text { area }}}_{A_{b t}}
$$

where $b \in i$ denotes the census tracks included in city $i$.

Discretizing the variable. We see that $\widetilde{Z}_{i t}$ is in principle continuous between 0 and $1 . \widetilde{Z}_{i t}$ will be equal to one if all of its areas have had access for the entire year. It will be equal to $1 / 2$ if the entire city has had access to broadband over half the year $t$.

While the continuous measure is useful, as it allows to gauge the state of broadband penetration, we do not use it directly in our empirical estimations. Indeed, regressing trade outcomes on this measures would assume that the effect of an increase $\widetilde{Z}_{i t}$ by, say 0.5 , will be the same whether it stems from an coverage of the whole city over half the year or an increase in half the city area of the entire year. As we do not have strong theoretical reason to think that would be the case, but we still believe that the two sources of information are valuable, we discretize the treatment status by setting treatment status to 1 after the city experienced its highest increase in $\widetilde{Z}_{i t}$. Formally, we define the year of treatment as $t_{i 0}=$ $\operatorname{argmax}_{t} \Delta \widetilde{Z}_{i t}$ and discretized treatment status as $Z_{i t}=\mathbb{1}\left\{t \geq t_{i 0}\right\}$.

As seen from Figure 1 in practice the empirical distribution of $\widetilde{Z}_{i t}$ is heavily concentrated on 0 and 1 and accordingly $Z_{i t}$ and $\widetilde{Z}_{i t}$ are strongly related $(\rho=0.90)$. Another way to assess the relationship between the continuous and discrete variables is to trace the evolution of $\widetilde{Z}_{i t}$ around $t_{i 0}$. Figure A1 plots the coefficients of a regression of $\widetilde{Z}_{i t}$ on a set of dummies for each time with respect to $t_{i 0}$. The results show a sharp increase between -1 and 0 from 0 to 0.4 and to 0.9 at +1 . The coefficients are estimated with a very high degree of precision which reflects the fact that $\widetilde{Z}_{i t}$ while continuous in theory has most of its support in 0 or 1 .

We therefore discretize the variable since it does not result in much information loss and it allows us to use the more transparent event-study approach that will be described in Section 4 .

Geographical description of broadband expansion. Figure 2 shows the roll-out for all of France. Figure OA.2 in the Online Appendix focuses on a specific region (Occitanie) in order to provide a sense of the large variation in treatment 
Figure 1: Distribution of $\widetilde{Z}_{i t}: 1999-2007$

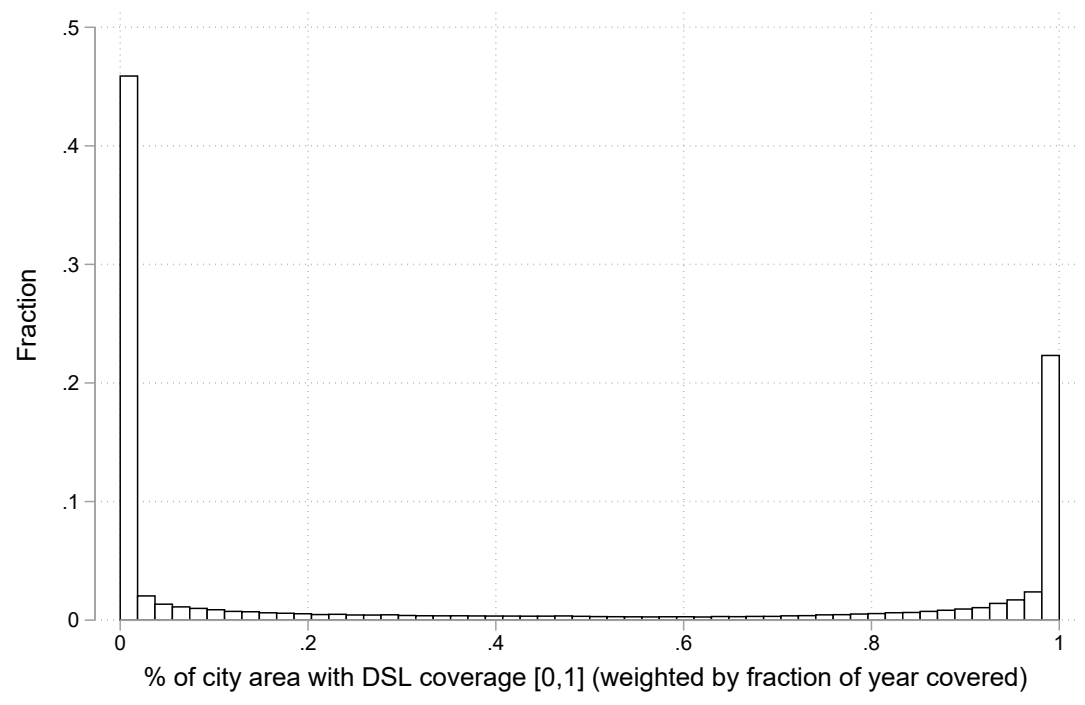

NOTES: This figure plots the distribution of the continuous measure of local broadband availability (variable $\widetilde{Z}$ ) as defined in Equation (1). We see that while the measure is continuous and contained between 0 and 1 but presents point of accumulation on 0 and 1.

status over time at very fine-grained geographical level. The dark areas represent a large degree of coverage (a high $\widetilde{Z}_{i t}$ ). In 2000, those are confined to the few major cities of France, surrounded by a large majority of no-ADSL territories. By 2003, the treatment has largely spread to lower scale-municipalities, although large parts of France remain dependent on the old technology. The national territory is essentially "hole-free" in 2007, when almost all LEs have been dealt with. Our empirical approach will take account of the fact that all cities are eventually treated in our setup.

Figure 2: The progressive roll-out of the DSL technology in France $-\widetilde{Z}$
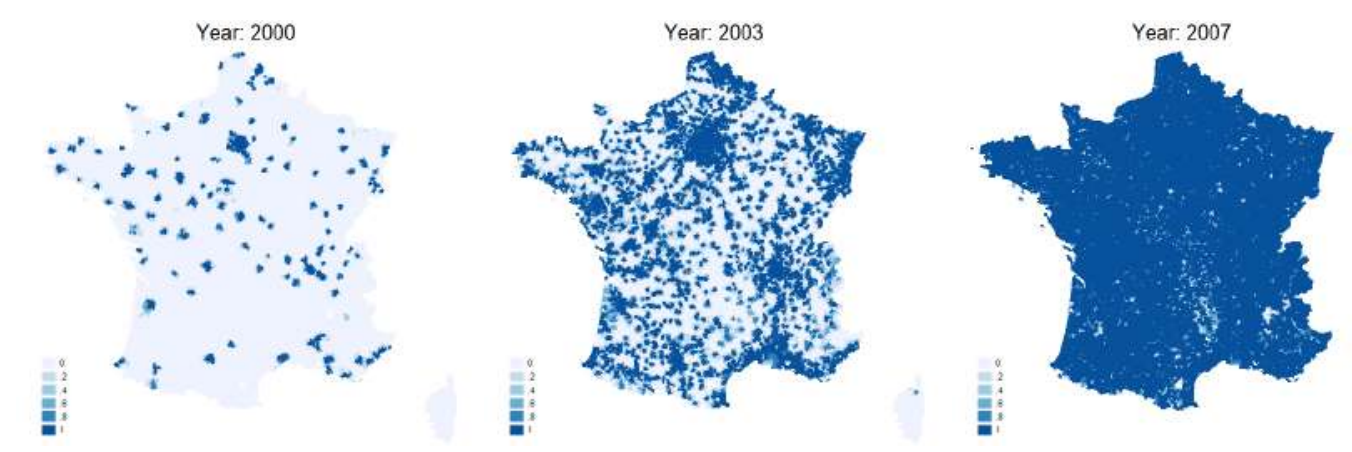

NOTES: This figure presents the geographical distribution of the continuous measure of local broadband availability (variable $\widetilde{Z}$ ) as defined in Equation (1). 


\subsubsection{Trade and employment data}

(i) Firm-level trade data. The data on firm-level trade is produced by the customs office, and compiles the exported values and quantities for each firmdestination-product combination over the period considered (1997-2007).

(ii) Firm-level employment and location data. The administrative dataset DADS (Déclarations Annuelles de Données Sociales) comes from firms' social security records. For the period 1997-2007 and for every establishment with at least one employee, it provides the number of workers, the overall wage bill and the city of location. This is an establishment-level dataset where a firm can have several establishments.

(iii) City-level covariates. Several covariates (population, share of college-educated workers, labor force) come from the 1999 census files aggregated at the city level and directly provided by the French statistical institute (INSEE) on its website. Additional covariates (number of households and overall tax income) come from tax authorities' files aggregated at the city level (Fichier communal de l'impôt sur le revenu).

\subsubsection{Balance-sheet data}

We use a firm-level balance sheet dataset from France. The firm-level accounting information is obtained from the BRN ("Bénéfices Réels Normaux") dataset which contains the balance sheet and income statement of all firms operating under the standard corporate income tax regime. The BRN dataset gathers information on about than 600,000 French firms every year. This dataset has been used in several trade-related papers dealing with French data (e.g. Eaton et al., 2011; Mayer et al., 2014). We use this dataset to compute firm-level performance measures (sales, value-added) as well as the relative importance of imports (importsover-sales ratio). These measures will be particularly useful when linking our empirical results to the conceptual framework.

\subsubsection{Construction of the estimating sample}

We assemble those different data sources to construct a final city-level estimating sample. We start with the administrative dataset DADS to keep in our working sample only mono-city and mono-establishment firms. This is done in order to precisely identify the impact of broadband internet availability on trade outcomes (we want our treatment and outcomes to be at the same micro level). Indeed, 
while broadband internet expansion may occur at different moment for a same firm which owns several establishments in several cities, we only observe aggregate trade at the firm-level (the firm headquarter) and not at the establishmentlevel. Keeping only mono-establishment or mono-city firms addresses this potential measurement issue. Table 1 presents descriptive statistics at the city-level for our estimating sample. The average city hosts about 65 firms, 20\% of which on average belong to the manufacturing sector. Imports are positive for about $50 \%$ of observations. The ratio of imports to overall sales (weighted by sales) is equal to $5 \%$ on average. Its distribution is highly skewed. Individual cities represent on average a small percentage of sales of overall sales $(0.42 \%)$. This provides indirect support to the notion that broadband expansion of any given city is unlikely on average to have a major competitive impact on firms located in other cities.

Table 1: Descriptive statistics at the city-level: 1997-2007

\begin{tabular}{lccccc}
\hline \hline & & & & & \\
& Mean & p25 & p50 & p75 & p95 \\
\hline Nb. firm (by city) & 65 & 7 & 14 & 37 & 194 \\
Sh. of mfg. firms & 0.2 & 0.0 & 0.1 & 0.4 & 0,8 \\
Import share (wrt. sales) & 0,05 & 0.0 & 0.0 & 0.04 & 0.22 \\
Sales as \% of departement sales & $0.42 \%$ & $0.01 \%$ & $0.04 \%$ & $0.17 \%$ & $1.62 \%$ \\
\hline \hline
\end{tabular}

NOTES : This table presents some descriptive statistics at the city-level on our estimating sample for 26,372 cities over the $1997-2007$ period (245,511 obs.). The share of importing cities is the mean of a dummy equal to one if at least one firm was an importer on year $t$ in city $i$, and zero otherwise. The import share is the city-level ratio of the value of imports over sales

We compute the value of imports, the quantity of imports, the number of importing flows and the number of different products imported for mono-city firms aggregated at the city-level and for several geographic areas and products categories (as defined by the BEC). We merge this trade database with broadband internet data. We then aggregate firm-level balance sheet data from the BRN at the city-level and merge this additional information with our main database - we restrict the BRN sample to single-city firms present in the DADS. Finally, we use firm-level employment and location data, data on population, share of college educated workers, labor force from the 1999 census files as well as number of fiscal households and overall fiscal income from fiscal files aggregated at the city level to construct a large fiscal and demographic control database that we merge with our trade working sample. We keep cities that do not undergo a change in geography over the period. 


\section{Empirical approach}

As mentioned earlier, our empirical setting does not fit the standard differencein-differences setting because all units are ultimately treated, i.e. connected to broadband internet over the period we consider. We therefore exploit variation in the timing of treatment which was staggered over time.

\subsection{Baseline specification}

In light of the issues associated with the static two way fixed-effects in the staggered treatment setting (Goodman-Bacon, 2018; Borusyak and Jaravel, 2017), we estimate a dynamic specification where we allow the effect on a city $i$ / year $t$, to vary with time-from-treatment. The year of treatment for each city is denoted $t_{i 0}$. We index time-to-treatment with $d$ (negative before treatment, negative after). Our sample covers the years 1997 to 2007, and we restrict the set of observations to the ones where $d \in\{-6,+5\}$. The main estimating equation is as follows:

$$
Y_{i t}=\sum_{\substack{d=-5 \\ d \neq-1}}^{d=5} \beta_{d} \times \mathbb{1}\left\{t=d+t_{0 i}\right\}+\mathbf{x}_{i t}^{\prime} \boldsymbol{\delta}+\alpha_{i}+\psi_{r(i), t}+\varepsilon_{i t},
$$

where $\alpha_{i}$ and $\psi_{r(i), t}$ are fixed effects for the city and for the département (of the city)-year, and $\mathbf{x}_{i t}^{\prime}$ is a vector of time-dependent city-level covariates. We drop two indicator variables for $d=-6$ and $d=-1$. That restriction is necessary to avoid multi-collinearity and to identify the fully-dynamic underlying data generating process in the staggered design (Gross et al., 2018; Borusyak and Jaravel, 2017). To ensure that this restriction is not driving our results, we display results with alternative normalizations in the robustness section. ${ }^{14}$

The specification presented in equation (2) includes leads and lags. The inclusion of leads allows us to assess the presence of pre-trends. However, in order to maximize efficiency, we also include a semi-dynamic specification where only the lags of the treatment are included, as presented in equation (3):

$$
Y_{i t}=\sum_{d=0}^{d=5} \beta_{d} \times \mathbb{1}\left\{t=d+t_{0 i}\right\}+\mathbf{x}_{i t}^{\prime} \boldsymbol{\delta}+\alpha_{i}+\psi_{r(i), t}+\varepsilon_{i t} .
$$

\footnotetext{
${ }^{14}$ We assess the sensitivity of our results to binning the coefficients associated with period -6 to 4 together, meaning to constraint them to be equal as in (Schmidheiny and Siegloch, 2019). Finally, note that the semi-dynamic specifications are not subject to this under-identification problem.
} 
This empirical model enables us to assess the dynamics of the treatment effect in the short and medium run (up to five periods after the expansion).

Interpretation. The event-study coefficients $\widehat{\beta}_{d}$ in equation (2) can be interpreted causally under the identifying assumption that, conditional on receiving broadband over the period considered and conditional on city fixed-effects, the timing of broadband roll-out is unrelated to the outcome. The specification in equation (2) allows us to examine patterns in outcomes in the years leading up to the broadband expansion.

The identifying assumption that there is no systematic local factor driving both broadband and the trade outcome variables is extensively investigated by including flexible controls for shocks at the city level and assess the sensitivity of the coefficients.

\subsection{Validation of the research design}

Explaining broadband expansion. Our identification strategy hinges on the assumption that the coverage of cities is mostly determined by city population density - which is mostly fixed over time - and did not take into account underlying trends in trading / importing activities. As a result, conditional on city and year fixed-effects, we consider the variation in broadband access to be as good as random. In order to assess the validity of this assumption, we explore the extent to which broadband coverage over time is predicted by different types of lagged city-level covariates. We group explanatory variables into several groups:

1. Density: population in 1999 per square $\mathrm{km}(\log )$, interacted with a full set of year dummy variables.

2. Industry dynamics: shares of employment in 10 economic sector at $t-1$ as well as changes in shares between $t-1$ and $t-2$.

3. Trade: asinh(number of transactions), asinh(value of imports) in $t-1$, changes in these two variables between $t-1$ and $t-2 .^{15}$

We estimate the following specification:

$$
\tilde{Z}_{i t}=\operatorname{dens}_{i t}^{\prime} \boldsymbol{\rho}_{1}+\operatorname{indyn}_{i t}^{\prime} \boldsymbol{\rho}_{2}+\operatorname{trade}_{i t}^{\prime} \boldsymbol{\rho}_{3}+\mathrm{FE}_{i}+\mathrm{FE}_{r(i), t}+\varepsilon_{i t},
$$

\footnotetext{
${ }^{15}$ The asinh function is close to the logarithm function and allows us to include city with 0 trade in the analysis.
} 
where $\tilde{Z}_{i t}$ is the time-weighed share of city $i$ that is covered by broadband internet as described in Equation (1). As we are mostly interested in the explanatory power of these different groups of observable variables we only report the Rsquare of different sets of regressions. Individual coefficients are presented in the appendix.

Regression results. We start by regressing broadband internet coverage on all three sets of observable covariates without including any time or city fixed-effect. As indicated in Column (1) of Table 2, we obtain a R-square of 56\% indicating that these variables capture a substantial share of the variation in treatment status. Column (2) presents the R-square of two-way fixed-effect model including city and province $\times$ year fixed effects. This model absorbs $78.6 \%$ of the variance in treatment intensity. Column (3) presents the same model to which is added the 1999 measure of density interacted with year dummies. The fit of the model increase by $2.6 \mathrm{pp}$. Interestingly, the set of industry dynamic or trade variables barely increase the fit of the model (columns 4 and 5), indicating that conditional on city and province-year fixed effect, they are roughly unrelated to the timing of internet coverage. We consider the low predictive power of observable variables as supporting our identification strategy, as a large share of the variation in timing of the broadband expansion seems to be idiosyncratic in nature. ${ }^{16}$

Table 2: Explaining city broadband coverage: panel analysis

\begin{tabular}{|c|c|c|c|c|c|c|}
\hline & $\begin{array}{c}(1) \\
\text { Covariates }\end{array}$ & $\begin{array}{c}\text { (2) } \\
\text { Twoway FE }\end{array}$ & $\begin{array}{c}(3) \\
(2)+\text { density }\end{array}$ & $\begin{array}{c}(4) \\
(2)+\text { indus. }\end{array}$ & $\begin{array}{c}\text { (5) } \\
\text { (2)+trade. }\end{array}$ & $\begin{array}{c}(6) \\
(2)+\text { all cova. }\end{array}$ \\
\hline$R^{2}$ & 0.563 & 0.786 & 0.812 & 0.786 & 0.786 & 0.812 \\
\hline \multicolumn{7}{|c|}{$\begin{array}{l}\text { NOTES : This table presents the R-square of panel regressions following equation (4). Twoway FE } \\
\text { (Column 2) refers to a twoway fixed-effect model with city fixed effect and département } \times \text { yea } \\
\text { FEs. Density (Column 3) includes } 1999 \text { population density at the city level defined as \#. of inhabi } \\
\text { tant divided by city area interacted with year indicators. Industrial structure controls (Column } 4 \\
\text { include the lagged share and their changes of sectoral shares (nine sectors). Trade controls include } \\
\text { the lagged log of trade value and number of flows (levels and changes). Column (1) includes all o } \\
\text { the controls without fixed effects. Individual coefficients are reported in Table A5 of the Appendix }\end{array}$} \\
\hline
\end{tabular}

Our baseline specification will allow for differential (linear and quadratic) trends in outcomes based on initial density. We will further assess the sensitivity of coefficients to the inclusion of observables and show that results are little affected by their inclusion. Naturally, this test does not imply that unobservables are not biasing our estimated coefficients. However for this to be the case, these

\footnotetext{
${ }^{16}$ Full regression results are displayed in Table A5. Trade and industry lagged level and dynamics are almost all insignificant once fixed-effects are introduced (column 6 of A5).
} 
unobservables should be time-varying, correlated with the timing of broadband expansion and yet uncorrelated to the rich set of observable variables included whose inclusion we show does not affect our estimated coefficients. While this remains a possibility we cannot completely rule out, given the battery of robustness tests we provide, we view it as very unlikely.

\section{Baseline Results}

The main variable we consider is the value of imports (in logs) by a given city. We show the results for different specifications and assess the robustness of the results. We then turn to different margins of trade (extensive and sub-extensive margins).

\subsection{Value of imports}

Figure 3: Main specification: Log of the value of imports

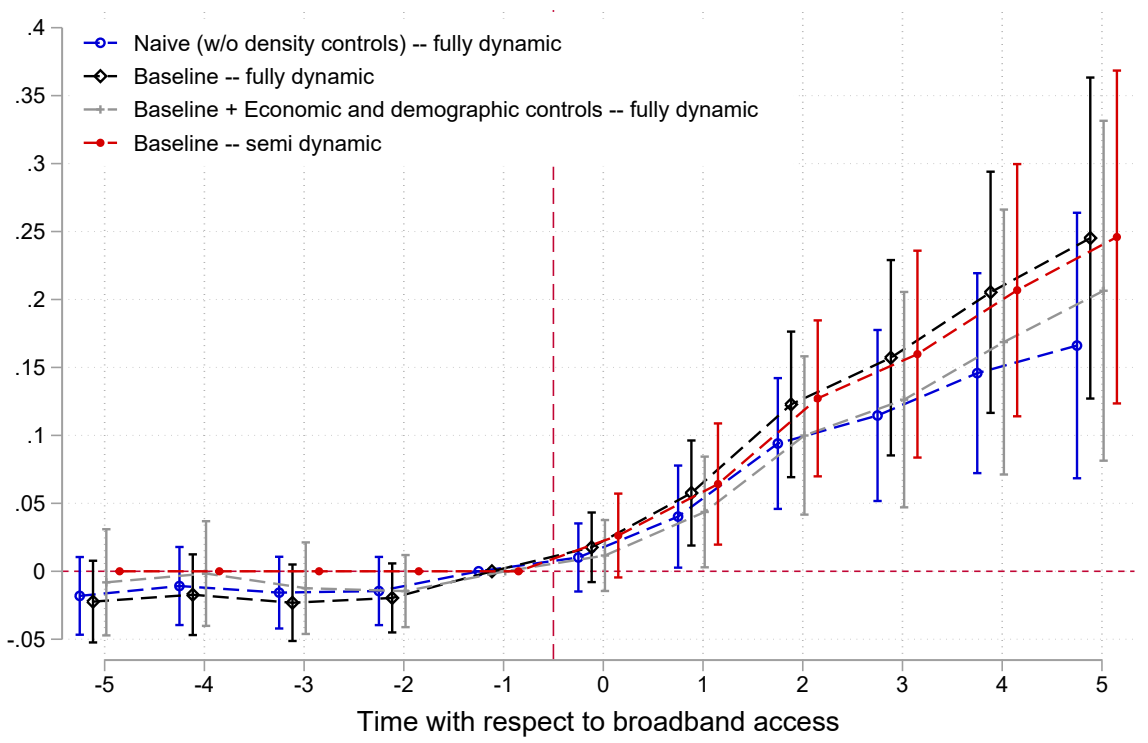

NOTES: This figure plots estimates for specification in equation ( 2 - fully dynamic) and ( 3 - semi dynamic). The sample include all cities with a positive trade flow (import).Density include 1999 population density at the city level defined as \# of inhabitant divided by city area interacted with quadratic and linear trends. Other controls include: (i) 1999 share of college educated workers interacted with year-dummies, (ii) the lagged share and their lagged changes of sectoral shares (nine sectors), (iii) lagged (log of) number of fiscal households and the average fiscal income (iv) 1999 education level interacted with year dummies (Share of dropouts). $95 \%$ confidence interval are presented. Standard errors clustered at the province (département) level. Full estimation results are reported in Table A1.

Figure 3 displays the main results of our paper, plotting estimated coefficients from Equation (2) (full results are presented in Appendix Table A1). The blue 
dashed line (with hollow circles) report results from a "naive" specification omitting controls except for the city and département-year fixed-effects. Estimates exhibit a flat trend before the event (i.e. the normalizing measure of time since access $d=-1$ ) and a break in the trend after that. The coefficient for $d=5$ in that specification is 0.162 suggesting that the expansion of access to broadband internet increased the overall value of city-level import by about $16 \%, 5$ years after the period of largest expansion (see column 2 of Table A1).

Given the relevance of density in the decision-making process leading to broadband expansion, our baseline specification adds linear and quadratic population density trends to the regression. The black line (with diamonds) shows our estimates. Here again, we see no sign of a pre-trend prior to broadband expansion opposed to a steady growth afterwards. The estimated effect after five years is substantially larger than in the naive case, with a coefficient of 0.25 .

The coefficients displayed with a light gray dashed line come from a third regression where controls for dynamics in sectoral composition, population and income (levels and dynamics) as well as initial educational level (share of collegeeducated) interacted with times dummies are included. Results are remarkably stable to this inclusion and are very close to the specification including only density controls. The estimated lead coefficients appear equally supportive of the absence of pre-trends. Finally, the last set of coefficients plotted in red represent a semi-dynamic version of the baseline specification. The regression should in theory more efficiently estimated -as the number of parameters to be estimated is lower-, however the standard errors turn out to be very close to the fully dynamic specification in practice.

We see that the estimated effects (independently of the chosen specification) are growing with time since broadband internet expansion in a roughly linear fashion. The effects grow in magnitude as time passes which suggests that they are structural and might affect the path of Note that the time period included in our analysis ends in 2007. This choice is dictated by the advent of the financial crisis which has a major negative impact on global trade (Baldwin, 2009) and would add noise to the estimation. ${ }^{17}$ Unfortunately it limits our ability to investigate the longer run effect of broadband expansion and whether it levels-off after a given

\footnotetext{
${ }^{17}$ It is standard for studies of empirical studies of international trade to exclude the great recession from their time window, see for instance Autor et al. (2013)'s seminal study of the China shock in the US.
} 
period of exposure. ${ }^{18}$

Magnitude of the effect. In order to give insights about the quantitative implications of our findings, we construct counterfactual aggregate imports absent broadband expansion. The counterfactual outcome is measured as the actual outcome minus the predicted effect of broadband availability on the outcome, taking into account the dynamics of the effects as captured by our semi-dynamic specification.

More specifically, we compute an average effect of broadband internet expansion for each year effect as $\bar{b}_{t}=\sum_{t_{0}=1999}^{2007} w_{t_{0}, t_{0}}^{y} \widehat{\beta}_{t-t_{0}}$ where $w_{t_{0}, t^{\prime}}^{y}$ represents the national trade share for outcome $y$ measured in $t^{\prime}$ for firms located in cities where broadband became available at year $t_{0}$. Let us denote the vector of total French imports over time as $y_{t}$. We postulate that the observed trade flow is given by a baseline level $y_{t}(0)$ that would have occurred in the absence of broadband diffusion multiplied by the predicted effect: $y_{t}=\exp \left(\bar{b}_{t}\right) y_{t}(0)$. We obtain the counterfactual series by inverting this relationship: $y_{t}(0)=\exp \left(-\bar{b}_{t}\right) y_{t}$.

We present two sets of counterfactual time-series in imports which corresponds to two different sets of weights $w$. The first is obtained by computing the weight for our estimating sample, which contains single-city firm only. The weights therefore do not sum to 1 for any given year but instead sum to the share of single-city firms in national imports.

The second approach normalizes the shares just mentioned so that they sum to $1 .^{19}$ Applying the first set of weights implicitly assumes that multi-city firms were not affected by broadband expansion in their importing behavior, while applying the second set is equivalent to assuming that they reacted in the same way as single-city firms. Therefore we see the first counterfactual as a lower bound while the second is more likely to be an upper bound. Indeed, to the extent that multi-city firms are larger and might be able to invest in technology and commercial networks that decrease their reliance on broadband technology to engage in international trade, the impact of broadband internet on their importing behavior is probably lower than the same effect for smaller, single-city firms.

The results are displayed in Figure 4. The lower bound result suggests that the increase in the real value of French imports, which was 91\% over the 1997-2007

\footnotetext{
${ }^{18}$ Note however that documenting an effect at a 5-year horizon in a event-study setting is rather on the upper bound of what is found in the literature. For instance, the seminal study by (Autor, 2003) bins effects 4 years or more after treatment.

${ }^{19}$ Formally, we define this second set of weights as : $\widetilde{w}_{t_{0}, t}=\left(\sum_{t_{0}} w_{t_{0}, t}^{y}\right)^{-1} \times w_{t_{0}, t}$.
} 
period, would have been 15 p.p. lower without broadband expansion. The upper bound results suggests they would have been 37 p.p. lower.

Figure 4: Counterfactual aggregate trends in overall import

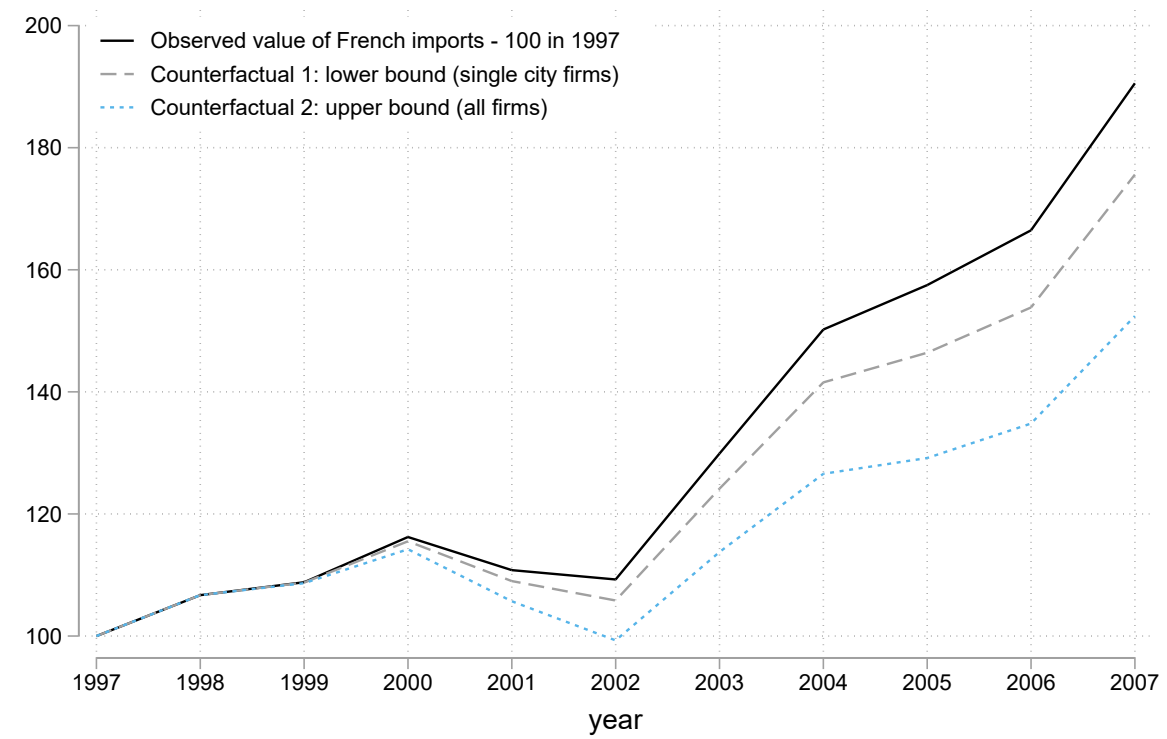

NOTES: The actual trade flows (black line) is the value of imports of goods in France in 2000 dollar normalized to 100 in 1997. Counterfactual 1 is obtained by subtracting the predicted effect of broadband internet where the average predicted effect is computed by using a weighted average of the estimated $\beta_{d}$, for $d \geq 0$ where the weights correspond to the share in national imports of each cohort of single-city firm (i.e. all single-city firms for which broadband expansion occurs the same year) measured the year of broadband expansion. The weights therefore do not sum to one and reflect the empirical importance of the estimating sample. Counterfactual 2 is obtained by doing the same calculation, but normalizing the previous weights so that they sum to one, thereby extrapolating the estimated effects outside of estimating sample onto all potential importer. See Magnitude of the effect: for more details.

Accounting for zero-flows. Our results so far do not include observations where the log of imports are not defined because imports are null. As such, there might be an extensive margin at the city-level that we are missing. A simple way to accommodate observations where city-level imports are null is to resort to the asinh(import) on a balanced sample of cities. ${ }^{20}$ Ashin() is defined as : $\operatorname{asinh}(z)=\ln \left(z+\sqrt{1+z^{2}}\right) \cdot{ }^{21}$ The results are displayed in Table A2 of the Appendix. Coefficients are larger $(0.38$ for $d=5$ instead of 0.25 for the baseline specification), suggesting a role for an extensive margin at the city-level. We will therefore investigate in more details the margisn of adjustment underpinning the overall positive effect of broadband expansion on imports in a dedicated section.

\footnotetext{
${ }^{20}$ For instance Hjort and Poulsen (2018) use this transformation when studying how individual hours worked are affected by the arrival of fast Internet.

${ }^{21}$ It is such that for $z \geq 2, \operatorname{asinh}(z) \approx \ln (z)+\ln (2)$ but with $\operatorname{asinh}(0)=0$
} 


\subsection{Further Robustness checks}

Local labor market dynamics. We saw above that including controls on sectoral employment dynamics leaves the results virtually unaffected. It could be however that our proxies do not fully capture local labor market shocks. In order to gauge the sensitivity of our results to the type of controls included, we control non-parametrically for any development at the local labor market level by including commuting-zone $\times$ year fixed effects. Commuting zone are defined based on a criterion of self-contained commuting and are the usual unit to study local labor markets in France. The estimated effects are displayed in Column 5 of Table A1 and are extremely close to the previous ones.

Alternative normalization. In the main analysis we normalize $\beta_{-6}$ and $\beta_{-1}$ to 0 . Here, we experiment with a different normalization: instead of assuming $\beta_{-6}=0$, we bin the coefficients associated with $d \leq-4$ together, that is we assume $\beta_{-6}=\beta_{-5}=\beta_{-4}$. Results are displayed in Table A3. Again, focusing on column 3 (density controls only), the estimated effect is very close to the one obtained previously ( 0.28 versus 0.25$)$. Overall, results do not appear sensitive to the choice of normalization.

Placebo inference. Bertrand et al. (2004) show that serial correlation can bias inference in difference-in-differences studies leading to serious over-rejection of the null hypothesis. We take this issue into account in our main analysis by constructing standard error that are clustered at the level of the département. These standard errors should lead to unbiased inference even in the presence of serial correlation within cities as well as cross-sectional dependence in the error term across cities within département.

In order to validate the inference provided by our clustered standard errors (which are only valid asymptotically) we implement Chetty et al. (2009)'s nonparametric permutation test of $\beta_{d}=0$ for $d=1,2,3,4,5$. To do so, we randomly reallocate the date of broadband expansion across cities, within the same département, and proceed to estimate equation (2). We repeat this process 2000 times and build an empirical CDF for $\widehat{\beta}_{d}$ which we denote $\widehat{F}()$. If broadband expansion has a truly significant positive effect on the dependent variable, here log of import values, one would expect the estimated coefficient to be in the very upper tail of the estimated empirical CDF based on permutations.

Denoting $\widehat{\beta}_{5}^{M}$ the point estimate obtained in Figure 3 based on the log value of imports, we get $1-\widehat{F}\left(\widehat{\beta}_{5}^{M}\right)=.0005$. Results are presented in Figure 5 . This p- 
Figure 5: Distribution of Placebo Estimates: Log Imports, $\beta_{5}$

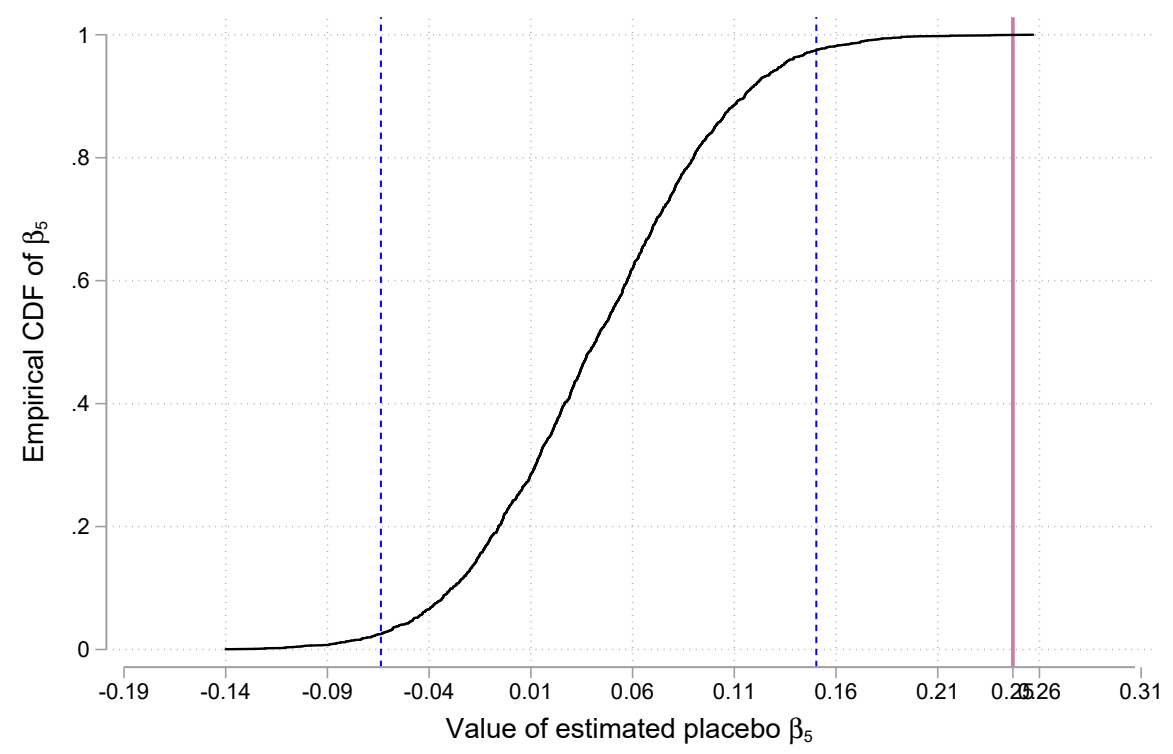

NOTES: This figure plots the empirical cumulative distribution function of placebo estimated effects broadband on log imports, where date of broadband expansion is randomly reallocated across cities within the same département (unit of cluster). Draws are with replacement and may include the correct date of treatment. The CDF is constructed from 2000 estimates of $\beta_{5}$ using the specification in equation (2) without observable controls. The solid line (in red) corresponds to the actual estimate of the matching specification. It lies outside of the $95 \%$ confidence interval that is delineated by the dashed lines (in blue).

value is smaller than the one using the t-statistics based on asymptotically-valid clustered standard errors (0.001) and confirm that the broadband internet led to an abnormally large increase in the value of imports. ${ }^{22}$

Restricting the sample period in order to obtain a proper control group. We check that using the continuous treatment measure in a simple fixed effect model over the period 1997-2004 leads to qualitatively comparable results. The restriction of this subsample period allows to consider cities that were never treated and therefore implement a classical difference-in-differences estimation. As expected, point estimates are smaller since they measure a shorter-run effect but they are positive and significant at conventional levels of confidence (see Table A4 in the appendix).

\footnotetext{
${ }^{22}$ The same holds for $\beta_{4}$ (see Figure OA.1 in the Online Appendix).
} 


\subsection{Intensive, extensive and sub-extensive margins}

We have at this stage established a strong effect of broadband internet on the value of imports at the city level. This pattern could be consistent with an increase in the number of importing flows, defined as a firm-origin country-product combination, an increase in the average value per flow or any combination of both.

Figure 6 show the results on both outcomes for the baseline specification. It is clear from those results that the average value per flow is virtually unaffected and that the effect on overall value is entirely driven by the increase in the number of flows.

Figure 6: Number of flows and average value per flow

(a) $\mathrm{Nb}$. of flows

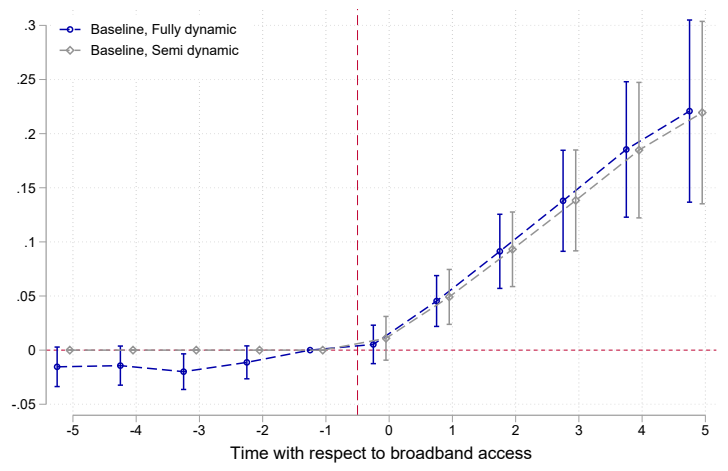

(b) Average value per flow

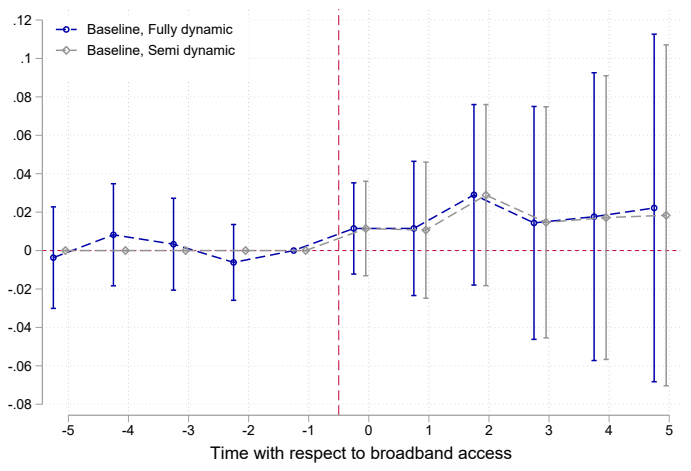

NOTES: This figure plots estimates for specification in equation ( 2 - fully dynamic) and ( 3 - semi dynamic). Baseline include 1999 population density at the city level defined as \# of inhabitant divided by city area interacted with quadratic and linear trends. $95 \%$ confidence interval are presented. Standard errors clustered at the département level. The sample include all cities with a positive trade flow (import).

The increase in the number of flows could in turn reflect either an increase in the number of importing firms or a rise in the number of importing flows per firm. We show that the first impact (extensive margin at the firm-level) is small in magnitude (about 6\%) albeit significant (see Figure 7). This implies that the second effect dominates: the "sub-extensive margin" (Gopinath and Neiman, 2014) explains most of the causal impact of broadband internet on the value of imports.

Our findings therefore support the notion that broadband internet caused an increase in import value, mostly by leading firms that were already importing to import more goods and from a wider array of origin countries while keeping the amount per flow roughly unaffected. This finding suggests that fixed costs play an important role in sourcing strategies (as in Antras et al., 2017) and also that broadband internet help to decrease such costs. The value per flow be- 
Figure 7: Extensive and sub-extensive margins

(b) Sub-extensive margins: flows per im-

(a) Extensive margin (at the firm level) porter
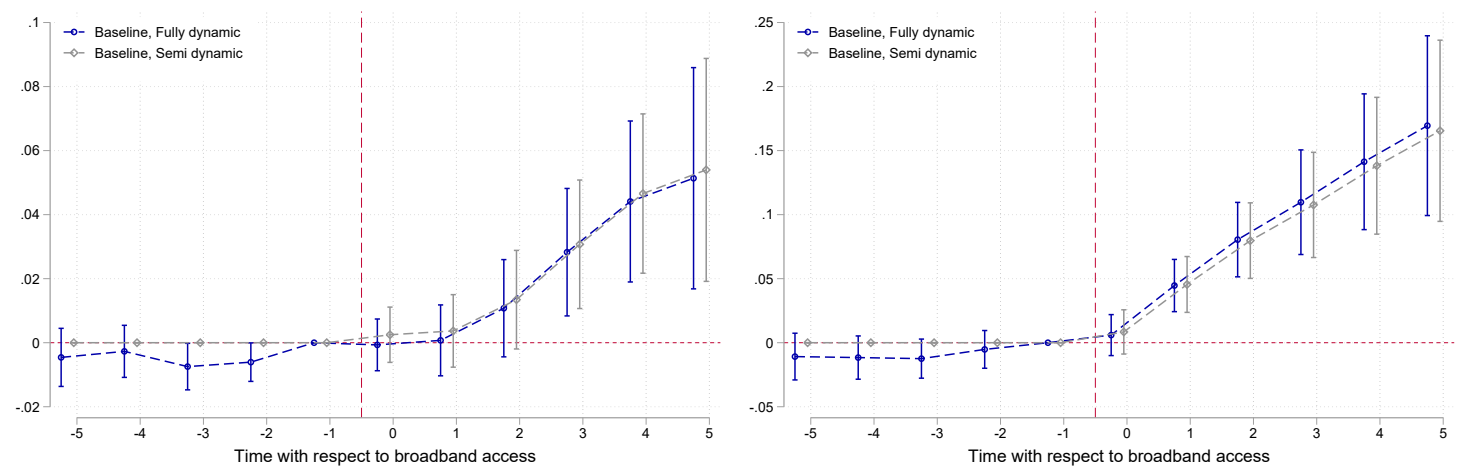

NoTES: This figure plots estimates for specification in equation ( 2 - fully dynamic) and ( 3 - semi dynamic). Baseline include 1999 population density at the city level defined as \# of inhabitant divided by city area interacted with quadratic and linear trends. $95 \%$ confidence interval are presented. Standard errors clustered at the département level. The sample include all cities with a positive trade flow (import).

ing unaffected, the increase in the amount spent on imports is roughly equal to the increase in the number of varieties imported - if one defines a variety as the unique combination of a product and a sourcing country as generally done in the literature (Broda and Weinstein, 2006).

Disentangling the rise in the number of products from the increase in the number of origin countries in the change in the total number of flows, Figure 8 shows that both margins appear relevant. 
Figure 8: Number of products (HS-6) and sourcing countries

(a) Number of products (HS-6)

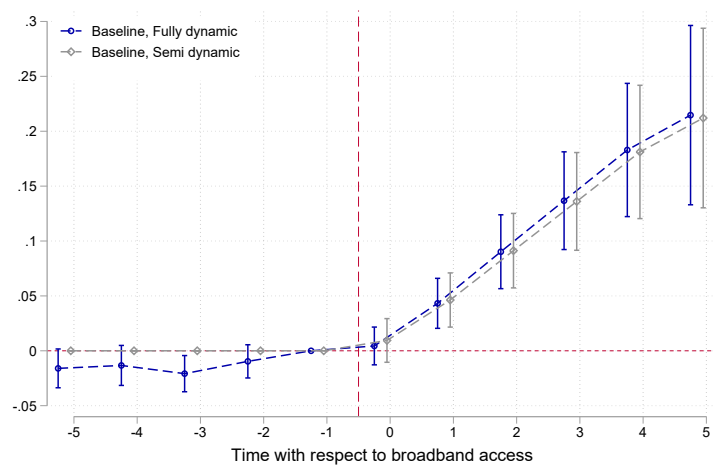

(b) Number of sourcing-countries

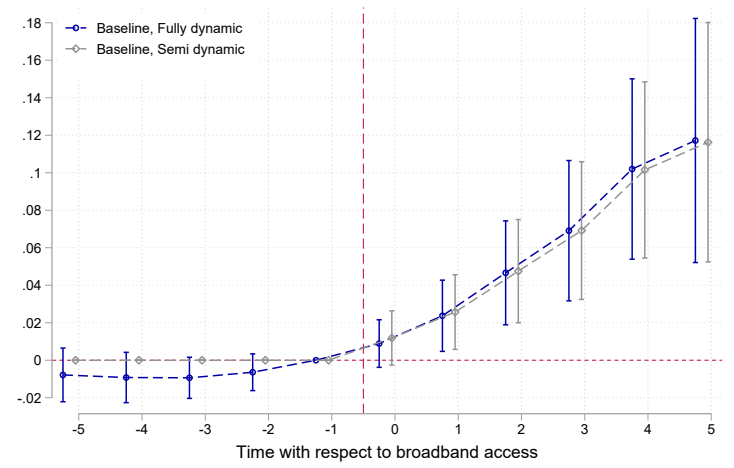

NOTES: This figure plots estimates for specification in equation ( 2 - fully dynamic) and ( 3 - semi dynamic). Baseline include 1999 population density at the city level defined as \# of inhabitant divided by city area interacted with quadratic and linear trends. $95 \%$ confidence interval are presented. Standard errors clustered at the département level. The sample include all cities with a positive trade flow (import).

\section{Heterogeneity and further results}

In this section, we present further results regarding the heterogeneity of the effects by origin country (subsection 6.1) and type of goods (subsection 6.2). We then present results on overall firm-level outcomes, namely sales and value-added (subsection 6.3). The latter results will be key inputs in our assessment of the impact of broadband on consumer welfare and the contribution of the import channel in the conceptual framework presented in Section 7.

\subsection{Origin-country}

Figure 9 recalls the overall effect on the value of imports after five years and then shows the results for different groups of origin countries. Overall, we fail to detect statistically significant heterogeneity, although point estimates appear larger for imports sourced from China and from Eastern European countries and somewhat smaller for EU-15 as well as other high-income countries and the rest of the world. 
Figure 9: $\widehat{\beta}_{5}$ for different groups of origin-countries

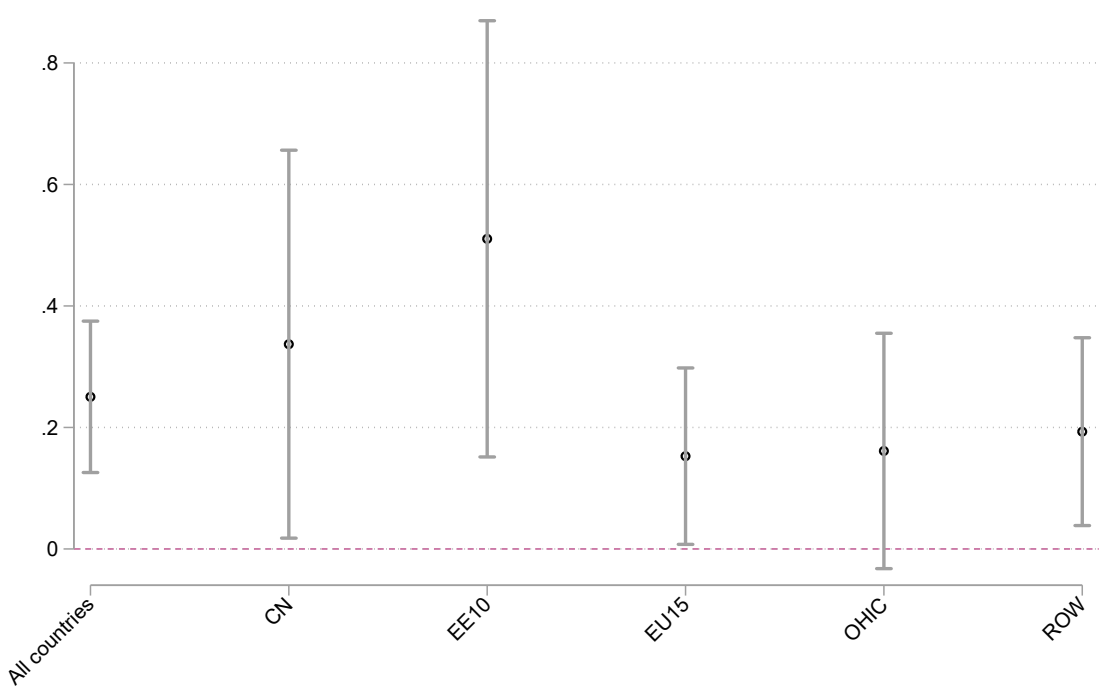

NOTES: This figure plots estimates $\widehat{\beta}_{5}$ from the specification in equation ( 3 - semi dynamic) for different groups of countries. Density controls. The sample include all cities with a positive trade flow (import).. CN = China, EE10 = Eastern European countries that joined the EU in 2004. OHIC other high income countries. ROW = rest of the world.

\subsection{Type of goods: capital, intermediary and consumption}

Figure 10 shows the overall effect on the value of imports classified in three different types of goods based on the BEC classification: capital goods, consumption goods and intermediary inputs. Those results display some heterogeneity between types of goods: the value of imports of capital goods are strongly impacted while we find a smaller effect, albeit still positive and significant, for intermediary inputs and consumption goods.

The literature on endogenous growth provides theoretical grounds for the role of foreign technology in enhancing domestic performance, notably through the import of capital goods (Eaton and Kortum, 2001). Our results imply that broadband internet might have boosted firm performance through that channel. To the extent that this channel is at work, one would expect firms sales and valueadded to be boosted by broadband internet. We now turn to such measures of firm performance. 
Figure 10: Value of imports by type of goods

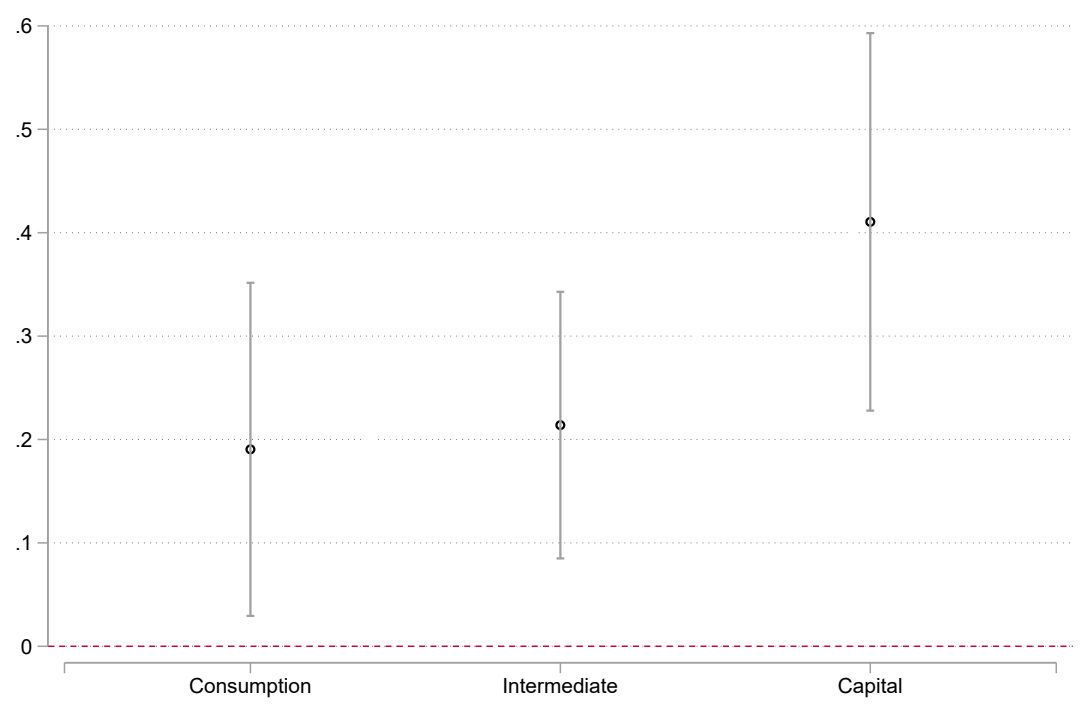

NotEs: This figure plots estimates $(t \geq 0)$ for specification in equation $(3-$ semi dynamic) and for goods grouped. Density controls. The sample include all cities with a positive trade flow (import).

\subsection{Impact on firm performance and import-intensity}

While trade is an important outcome in its own right, it is also interesting to see whether the increased imports of firms is associated with an expansion of overall activity as captured in their sales or value-added. The results, displayed in Figure 11 , show increase by $5 \%$ in sales and $6 \%$ in value-added.

Beyond the scale of economic activity, access to a broader range of inputs have been documented to increase productivity (Amiti and Konings, 2007; Topalova and Khandelwal, 2011). As most of the evidence focuses on the manufacturing sector (e.g. Halpern et al., 2015; Blaum et al., 2018) we split the analysis of productivity (value added per worker here) between the manufacturing and the nonmanufacturing sectors. Results in Figure 12 shows a positive effect of broadband expansion on the productivity of the manufacturing sector, but essentially no impact outside of the manufacturing sector where value-added and employment grew in the same proportions. The positive impact on firms' scale with no effect on the apparent productivity of labor in the non-manufacturing sector is consistent with previous work for the UK provided by DeStefano et al. (2018) who find a positive average treatment effect of ICT instrumented by local broadband 
Figure 11: Sales and value-added

(a) Sales

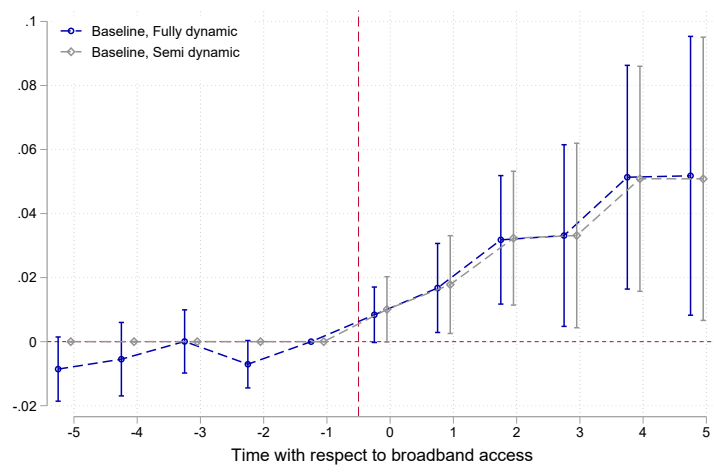

(b) Value-added

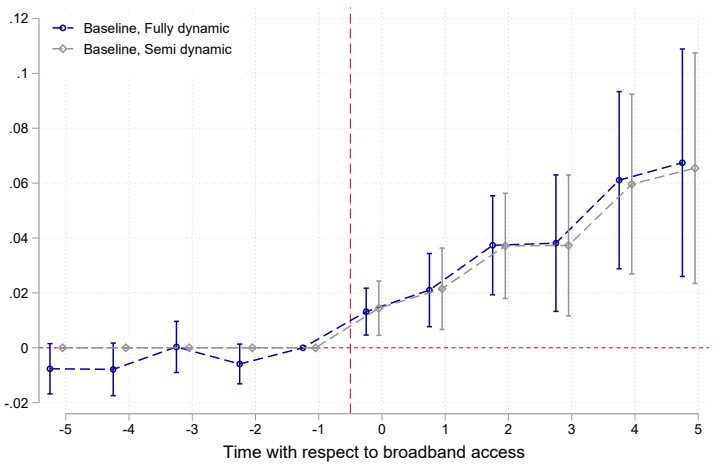

NOTES: This figure plots estimates for specification in equation ( 2 - fully dynamic) and ( 3 - semi dynamic). Baseline include 1999 population density at the city level defined as \# of inhabitant divided by city area interacted with quadratic and linear trends. $95 \%$ confidence interval are presented. Standard errors clustered at the département level. The sample include all cities with a positive trade flow (import).

\section{availability on firm's revenue and employment but not on different measures of productivity. ${ }^{23}$}

Figure 12: Value-added per worker

(a) Manufacturing sector

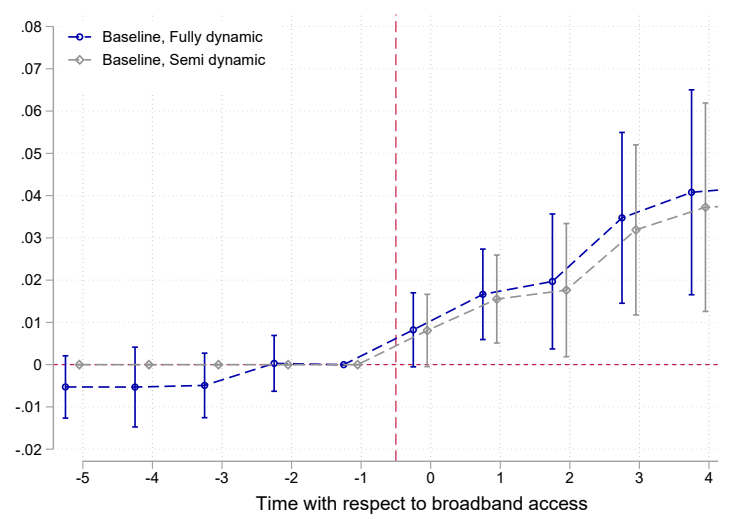

(b) Non manufacturing sector

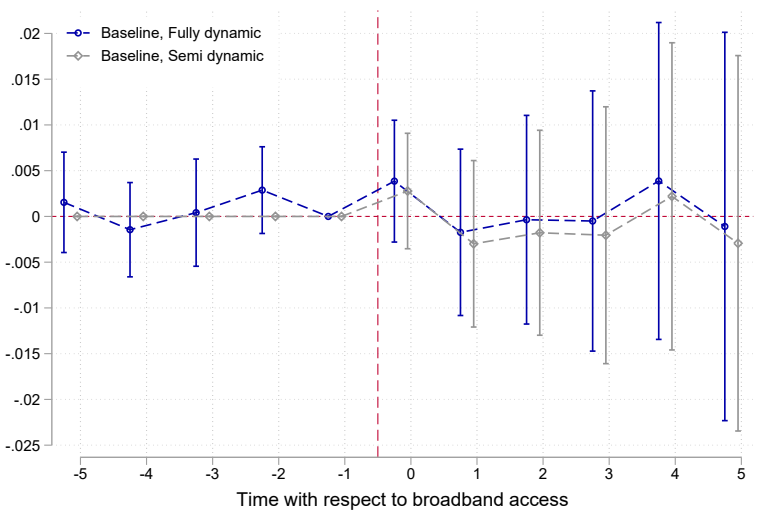

Notes: This figure plots estimates for specification in equation ( 2 - fully dynamic) and ( 3 - semi dynamic). Baseline include 1999 population density at the city level defined as \# of inhabitant divided by city area interacted with quadratic and linear trends. $95 \%$ confidence interval are presented. Standard errors clustered at the département level. The sample include all cities with a positive trade flow (import).

In the next section, we develop a conceptual framework where we can use our estimates to quantify (1) the overall effect of broadband internet on consumer

\footnotetext{
${ }^{23}$ They do not show long run effect on productivity by sector however.
} 
welfare and (2) isolate the contribution of the import channel to this overall effect. In doing so, we will need to know the effect of broadband internet on the imports over sales ratio. The results are presented in panel (a) of Figure 13 below. We obtain a point estimate of 0.15 after five years. In panel (b), we display results for the domestic share of inputs. ${ }^{24}$

From an empirical standpoint, measuring capital goods in the accounting data is delicate because they are likely to be accounted for as investment rather than as intermediate consumption and there is no distinction between domestic and foreign goods in the accounting data. Excluding capital goods allows us to make sure that the imports as documented in custom data contain goods comparable to intermediate consumption as documented in the accounting data.

We see a negative impact of about $-1.25 \%$ after five years. This result will play an important role in our welfare assessment below.

\section{Figure 13: Measures of import intensity}

(a) Imports over sales

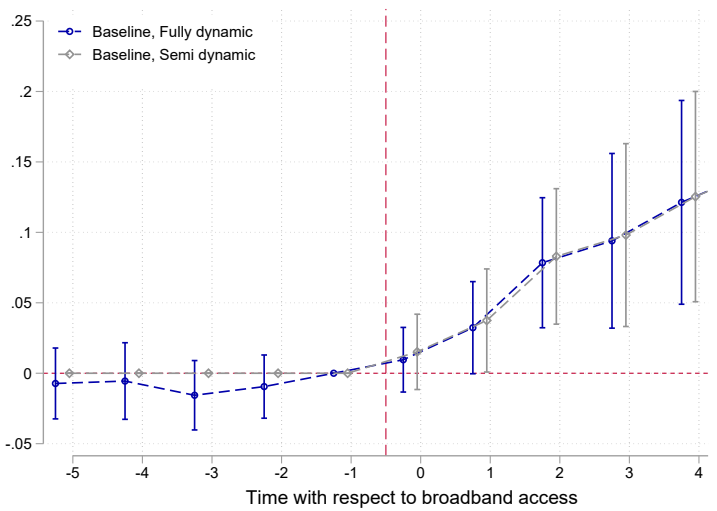

(b) Imports over intermediate consumption

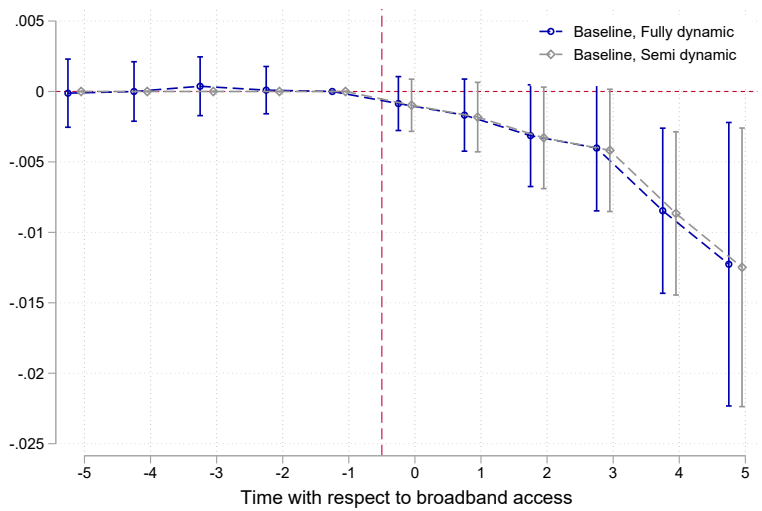

NOTES: This figure plots estimates for specification in equation ( 2 - fully dynamic) and ( 3 - semi dynamic). Baseline include 1999 population density at the city level defined as \# of inhabitant divided by city area interacted with quadratic and linear trends. $95 \%$ confidence interval are presented. Standard errors clustered at the département level. The sample include all cities with a positive trade flow (import).

\footnotetext{
${ }^{24}$ This share is computed as follow: $s d_{i t}=\frac{I C_{i t}-M_{i t}^{n}}{I C_{i t}}$ where $I C_{i t}$ is the value of overall intermediate consumption as reported in the income statement from the corporate tax return data and $M_{i t}^{n}$ is the value of imports as reported in the custom data where capital goods are excluded. We exclude capital goods from the custom data in order to make measurement from the two data sources comparable. Indeed, measuring capital goods in the accounting data is delicate because they are likely to be accounted for as investment rather than as intermediate consumption and there is no distinction between domestic and foreign goods in the accounting data. Excluding capital goods allows us to make sure that the imports as documented in custom data contain goods comparable to intermediate consumption as documented in the accounting data. Moreover, our conceptual framework below is static and abstracts away from capital goods.
} 


\section{Conceptual framework for quantification}

In this section, we set up a simple partial equilibrium model of firm-level importing that allows to quantify the magnitude of the import channel in terms of consumer welfare. We have empirically estimated the effect of BI on importing activities and sales. We show below that in a model featuring monopolistic competition and a CES demand system (MC-CES henceforth), we can recover the total effect of broadband on firm-level productivity (defined as the inverse of its unit-cost) from estimates of its impact on firm-level sales.

However, because broadband internet affects firm-performance through other channels than trade, it is not a suitable source of variation to instrument for import activities and understand its partial effect on unit cost. This is akin to a failure of the exclusion restriction leaving us with an under-identification problem: even if we know the total effect of BI on imports and productivity, we cannot isolate the contribution of broadband-induced imports to the overall effect of broadband internet on firm-level unit cost. To solve this problem, we add further structure on the production process and import environment, building on build on Blaum et al. (2018). In this simple theoretical framework, we show that a firm's observed domestic share of inputs (i.e. 1 minus its import share) encapsulates all of the effects of importing activities on its unit cost. Our main result is an expression for the the overall effect of broadband internet on the price index and the contribution of the import channel as a function of (i) firm-level effects of broadband internet on sales and the domestic share of inputs and (ii) structural parameters pertaining to preferences and technology. We use our reducedform estimates and calibrate the structural parameters based on previous works and/or aggregate data in order to quantify the effect of broadband internet on consumer welfare and the contribution of the import-channel.

\subsection{Demand and market structure}

The representative consumer (we do restrict attention to a single country of consumption, France in this case) has a classical Constant Elasticity of Substitution (CES, denoted $\sigma$ ) utility function over the set $\Omega$ of available varieties of a final good:

$$
U=\left(\int_{i \in \Omega} c_{i}^{\frac{\sigma-1}{\sigma}} d i\right)^{\frac{\sigma}{\sigma-1}}
$$

where $c_{i}$ is the quantity consumed of variety $i$. 
Those varieties are produced domestically under monopolistic competition. The CES demand function aggregated at the level of the nation yields sales $x_{i}$ for a variety (also a firm) $i$ :

$$
x_{i} \equiv c_{i} p_{i}=p_{i}^{1-\sigma} E P^{\sigma-1},
$$

where $E$ and $P$ respectively represent total expenditure and the ideal CES price index in this economy and $p_{i}$ represents the price of variety $i$.

Combined with monopolistic competition and constant marginal costs, the CES demand system implies a fixed markup over cost $\left(\frac{\sigma}{\sigma-1}\right)$, and therefore the values of sales writes as:

$$
x_{i}=u_{i}^{1-\sigma} \times S
$$

where $u_{i}$ refers to the unit cost of firm / variety $i$ and $S \equiv E P^{\sigma-1}\left(\frac{\sigma}{\sigma-1}\right)^{1-\sigma}$ is a market wide demand-shifter.

Imposing this simple structure, we aim to infer the effect of broadband internet on the unit cost for a given value of $\sigma$. Our estimate of the effect of BI on total sales $d$ years after broadband internet expansion is denoted as $\widehat{\beta}_{d}^{s}$. We will use our estimate of the long-run impact (after 5 years), $\hat{\beta}_{5}^{s}$. Using the sales equation (6), and assuming that the elasticity of substitution of the final good is left unchanged by the arrival of the internet, we can write:

$$
\ln \left(\frac{x_{i}(1)}{x_{i}(0)}\right)=(1-\sigma) \ln \left(\frac{u_{i}(1)}{u_{i}(0)}\right)+\ln \left(\frac{S(1)}{S(0)}\right)=\hat{\beta}_{5}^{s},
$$

where $X_{i}(1)$ and $X_{i}(0)$ are the potential values of the variable $X_{i}$ when $\mathrm{BI}_{c(i)}=1$ and $\mathrm{BI}_{c(i)}=0$ respectively ( $c$ is the municipality where firm $i$ is located). The small size of individual cities $c$ implies that each of them should have a negligible impact on the overall price index $P$ as well as on aggregate spending $E$, implying $\frac{S(1)}{S(0)} \approx 1 .{ }^{25}$ As a consequence, equation (7) implies that the sales effect of access to $\mathrm{BI}$ are attributed to a fall in costs in the city where firm $i$ is located and produces:

$$
\ln \left(\frac{u_{i}(1)}{u_{i}(0)}\right)=\frac{\hat{\beta}_{5}^{s}}{1-\hat{\sigma}}
$$

Combining our estimate of $\hat{\beta}_{5}^{s}$ with a value for $\hat{\sigma}$ (that one can take from the literature), equation (8) provides the total effect of $\mathrm{BI}$ on the reduction of unit costs.

\footnotetext{
${ }^{25}$ Given the small size of municipalities, BI-induced changes in local demand by customers within a given city should have a negligible effect on sales compared to the effect of BI on the supply side (i.e firm's unit cost). Moreover, the most likely effect of BI on local demand is to divert it away from local producers, reducing sales, going against our main mechanism.
} 
We now turn to consumer surplus. In this single sector model, the price index writes as:

$$
P=\left(\int_{i \in \Omega} p_{i}^{1-\sigma} d i\right)^{\frac{1}{1-\sigma}}=\frac{\sigma-1}{\sigma}\left(\int_{i \in \Omega} u_{i}^{1-\sigma} d i\right)^{\frac{1}{1-\sigma}} .
$$

The price index encapsulates all channels through which BI affects internet overall welfare through changes in unit costs.without and with BI respectively. Similar notation is used for unit costs $u_{i}(0)$ and $u_{i}(1)$. Consistent with our empirical analysis, we consider a multiplicatively constant treatment effect, i.e. $\psi_{i} \equiv$ $u_{i}(1) / u_{i}(0)=\psi, \forall i \in \Omega$. We denote $P(0)$ the price index when no firm has access to broadband internet, i.e. a fraction 0 of them, and symmetrically $P(1)$ the price index when all firms have access to broadband internet. We can thus write the change in the price index as:

$$
\ln \left(\frac{P(1)}{P(0)}\right)=\frac{1}{1-\sigma} \ln \left(\int_{i \in \Omega} \psi^{1-\sigma} \times\left[\frac{u_{i}(0)^{1-\sigma}}{\int_{i \in \Omega} u_{i}(0)^{1-\sigma} d i}\right] d i\right)=\ln \psi .
$$

Note that the $\frac{u_{i}(0)^{1-\sigma}}{\int_{i \in \Omega} u_{i}(0)^{1-\sigma} d i}$ term is equal to the market share of firm $i$ (in the absence of BI), which would weight the treatment in case of heterogeneity (firmlevel or spatial $\psi_{i}$ ). Because of the constant treatment effect assumption, we obtain an estimate of the change in the price index directly from our firm-level estimate of the impact of BI on sales: $\widehat{\ln \psi}=\hat{\beta}_{5}^{s} /(1-\hat{\sigma})$.

\subsection{Supply side 2: production function}

We now specify the production function and the import environment, building on Blaum et al. (2018)'s setup. Each firm operates a Cobb-Douglas production function combining labor and intermediate goods, with the exponent on labor denoted as $\gamma$ :

$$
Y_{i}=A_{i} L_{i}^{\gamma} X_{i}^{1-\gamma}
$$

where $Y_{i}$ refers to total physical production, $A_{i}$ is a term scaling the total factor productivity of the firm, $L_{i}$ is the effective quantity of labor, and $X_{i}$ the effective quantity of intermediate inputs. The parameter $\gamma$ determine the labor share in total costs. Intermediates can be either domestic or foreign and they are aggregated through a CES function with elasticity of substitution higher than unity:

$$
X_{i}=\left(\alpha_{i} X_{i, D}^{\frac{\varepsilon-1}{\varepsilon}}+\left(1-\alpha_{i}\right) X_{i, F}^{\frac{\varepsilon-1}{\varepsilon}}\right)^{\frac{\varepsilon}{\varepsilon-1}}
$$


where $X_{i, D}$ is the quantity of domestic inputs while $X_{i, F}$ refers to the quantity of imported inputs. The parameter $\varepsilon>1$ determines the elasticity of substitution between foreign and domestic inputs. Finally, the foreign input $X_{i, F}$ itself aggregates imported varieties through a constant return to scale production function $G_{i}()$ which can be firm-specific:

$$
X_{i, F}=G_{i}\left(\left\{q_{o} X_{i, o}\right\}_{o \in \Omega_{i}}\right)
$$

Foreign inputs $X_{i, o}$ are indexed according to their country of origin $o$. The term $q_{o}$ parameterizes the relative efficiency of inputs from country $o . \Omega_{i}$ refers to the set of countries from which the firm sourced its goods or sourcing strategy and is potentially an endogenous variable (as in Antras et al., 2017, for instance) .

\subsection{Sufficiency result}

In that setting, conditioning on the set of sourcing countries $\Omega_{i}$, the unit-cost is given by:

$$
u_{i} \equiv\left\{\min _{L, X} L w+X_{D} p_{X_{D}}+\sum_{c \in \Omega_{i}} X_{F, c} p_{F, c}, \text { s.t. } Y_{i} \geq 1\right\}
$$

where $p_{F, o}$ is the price of input varieties imported from $o$. We can define the (ideal) import price index as the ratio of the spending on imports over the effective quantity of imports as defined in (13):

$$
\mathbf{p}_{i}\left(\Omega_{i}\right) \equiv E_{i, F} / X_{i, F}
$$

where $E_{i, F}$ denotes spending on foreign goods by firm $i$. Note that we leave, for now, the function $G_{i}()$ unspecified. However for most plausible aggregators, $\mathbf{p}_{i}\left(\Omega_{i}\right)$ will be declining in the cardinality of $\Omega_{i}\left(\left|\Omega_{i}\right|\right)$, meaning that the effective price index of imports will decrease in the number of sourcing countries.

In the presence of fixed cost of importing that is paid per destination, there is a trade-off between higher payment towards origin-specific fixed costs of importing and the resulting reduction in the price index of imported goods which ultimately translates into lower overall unit cost. This can occur in Armingtontype models where inputs are differentiated by country of origin, thus creating a love-for-variety effect (Halpern et al., 2015; Sandoz, 2017) or in models where expanding the set of sourcing countries allows accessing cheaper quality-adjusted inputs (Antras et al., 2017). 
Given the price index of imports $\mathbf{p}_{i}\left(\Omega_{i}\right)$, and the CES aggregation of foreign and domestic inputs, we can express the price index of all intermediates as:

$$
Q_{i}\left(\Omega_{i}\right)=\left(\alpha_{i}^{\varepsilon} p_{X_{D}}^{1-\varepsilon}+\left(1-\alpha_{i}\right)^{\varepsilon} \mathbf{p}_{i}\left(\Omega_{i}\right)^{1-\varepsilon}\right)^{\frac{1}{1-\varepsilon}}
$$

Finally, given the Cobb-Douglas assumption at the upper level, it is straightforward to express unit cost as:

$$
u_{i}=(1-\gamma)^{-(1-\gamma)} \gamma^{-\gamma} \times A_{i}^{-1} Q_{i}\left(\Omega_{i}\right)^{1-\gamma} w^{\gamma}
$$

Given the CES aggregation between domestic and foreign inputs, we can express the equilibrium share of domestic inputs as:

$$
s d_{i}=\alpha_{i}^{\varepsilon} p_{X_{D}}^{1-\varepsilon} Q_{i}\left(\Omega_{i}\right)^{\varepsilon-1}
$$

where $s d_{i} \equiv p_{X_{D}} X_{D, i} /\left(X_{F, i} \mathbf{p}\left(\Omega_{i}\right)+p_{X_{D}} X_{D, i}\right)$ is the fraction of firm spending on intermediates that goes toward domestic inputs. We can relate unit cost and domestic share of intermediate inputs by inverting the expression above and substituting for $Q_{i}\left(\Omega_{i}\right)$ into the expression for the unit cost:

$$
u_{i}=\tilde{A}_{i}^{-1} s d_{i}^{\frac{1-\gamma}{\varepsilon-1}} p_{X_{D}}^{1-\gamma} w^{\gamma}
$$

where $\tilde{A}_{i}=A_{i}\left(\alpha_{i}\right)^{\frac{\varepsilon(1-\gamma)}{\varepsilon-1}}(1-\gamma)^{1-\gamma} \gamma^{\gamma}$. Equation (17) is essentially a sufficiency result, as first demonstrated by Blaum et al. (2018) (see their equation 6), stating that conditional on its domestic expenditure share (i.e. 1 minus the importing share), the rest of the import environment (including the global sourcing strategy $\Omega_{i}$, prices $p_{o i}$ or the technology through which foreign goods are agregated $\left.G_{i}()\right)$ does not affect the firm's unit cost. The domestic expenditure share conveys all the information from the inputs importing activity that is relevant for the unit cost. ${ }^{26}$ Note that this sufficient statistic result does not depend on a specific market structure assumption regarding the final good. Opting for CES preferences with monopolistic competition as we do is needed to set a one-to-one mapping from changes in unit cost to changes in consumer prices, shown in section 7.2.

\subsection{Broadband expansion and the sufficiency result}

We can now think of BI expansion and of its impact on unit cost in this setting. BI expansion is likely to affect $u_{i}$ through several channels. It could for instance

\footnotetext{
${ }^{26}$ We present the sufficiency result in a very simplified import environment (Armington model with a continuum of homogeneous countries with homogeneous variables and fixed costs for importing) that allows for a simple closed-form solution in the Online Appendix OA.2.
} 
affect $A_{i}$ directly, or reduce the effective price of labor $w$ through skill-biased technical progress (Akerman et al., 2015). As we have documented, BI has also increased spending on imports as well as other margins of trade. In this setting, for the purpose of understanding the unit cost effect of BI through changes in the import environment, we solely need to know the effect of BI on the domestic share of inputs $s d_{i}$. In other words, in this setting the domestic share is a sufficient statistic for the effect of trade in inputs on unit costs. As a result, the impact of broadband internet on the import share is a sufficient statistic for the part of the effect of broadband internet on the unit cost that is channeled through changes in the importing behavior. So far as unit cost reduction is concerned, it does not matter how BI affects the import share of inputs, e.g. whether through a reduction in the fixed cost of importing or through variable costs. All that matters is how much BI affects the domestic (or import) share.

We start by considering the overall effect of $\mathrm{BI}$ on the unit cost. Using equation (17) and maintaining the notation (0) and (1) for the potential outcomes taken without and with $\mathrm{BI}$ respectively, we obtain:

$$
\begin{aligned}
\underbrace{\ln \left(\frac{u_{i}(1)}{u_{i}(0)}\right)}_{\text {total effect }} & =\underbrace{\ln \psi}_{\text {import channel }} \\
& =\underbrace{\frac{1-\gamma}{\varepsilon-1} \ln \left(\frac{s d_{i}(1)}{s d_{i}(0)}\right)}_{\text {residual effect }} \\
& +\underbrace{\gamma \ln \left(\frac{w(1)}{w(0)}\right)+(1-\gamma) \ln \left(\frac{p_{X_{D}}(1)}{p_{X_{D}}(0)}\right)-\ln \left(\frac{\tilde{A}_{i}(1)}{\tilde{A}_{i}(0)}\right)},
\end{aligned}
$$

where the third term refers to all the mechanisms other than the import channel, while the import-channel is fully summarized by $\frac{1-\gamma}{\varepsilon-1} \ln \left(\frac{s d_{i}(1)}{s d_{i}(0)}\right)$. The first equality comes from the constant treatment effect assumption that we maintain throughout. $^{27}$

\section{Mapping reduced-form estimates of BI into welfare effects}

\footnotetext{
${ }^{27}$ Note that we take $\gamma$ here to be a policy invariant parameter. This assumption appears at odds with the empirical findings of Fort (2017) who shows that ICT adoption in the US increases the probability of both domestic and foreign sourcing by firms. Her results would suggest a positive effect of broadband expansion on $1-\gamma$. However, in our application, we do not find any effect of broadband internet on the empirical counterpart of $1-\gamma$. The point estimate after 5 periods is -0.004 with $95 \%$ confidence interval: $(0.0036,-0.0116)$. Results are displayed Figure OA.3 of the online appendix. It seems therefore warranted to model $\gamma$ as a fixed (i.e. treatment invariant) parameter.
} 
We now aim to relate our results to the strength of the import channel. The impact of broadband internet on the decline in unit cost that goes through the import channel (via an increased access to foreign intermediates), can be expressed as:

$$
\text { Import Channel }=\frac{1-\gamma}{\varepsilon-1} \ln \left(\frac{s d_{i}(1)}{s d_{i}(0)}\right)=\frac{1-\gamma}{\varepsilon-1} \times \beta_{5}^{s d}
$$

where $\beta_{5}^{s d}$ refers to the 5-year horizon effect of BI on the log of the domestic share $s d$. The overall contribution to the decline in unit cost can be expressed as:

$$
\ln \left(\frac{u_{i}(1)}{u_{i}(0)}\right)=\ln \psi=\frac{1}{1-\sigma} \ln \left(\frac{x_{i}(1)}{x_{i}(0)}\right)=\frac{\beta_{5}^{s}}{1-\sigma},
$$

where $\beta_{5}^{s}$ refers to the 5 -year horizon effect of $\mathrm{BI}$ on the log of sales. Given our estimate $\widehat{\beta}_{5}^{s}$ and assuming $\sigma=4$, we have: ${ }^{28}$

$$
\text { Total effect }=\ln \left(\frac{u_{i}(1)}{u_{i}(0)}\right)=\frac{\beta_{5}^{s}}{1-\sigma}=\frac{0.05}{1-4}=-1.7 \% .
$$

To locate this estimate in the literature, we note that the figure of $-1.7 \%$ is about half the productivity effect estimated by Akerman et al. (2015) in Norway. They found that a $10 \%$ increase in broadband availability is associated with a $0.4 \%$ increase in productivity (as measured by overall production holding inputs constant), suggesting a $4 \%$ increase when broadband availability goes from 0 to $100 \%$.

For the value of $\varepsilon$, we rely on Blaum et al. (2018) - whose estimation is also carried out on French data for a comparable period (2000-2006). For the overall economy we retain $\varepsilon=2.3$. The model implies: $1-\gamma=\frac{\text { expenditure on intermediates }}{\text { sales }} \times \frac{\sigma-1}{\sigma}$. Using the sample average of the ratio of spending on intermediates over sales and $\sigma=4$ yields $1-\gamma=0.5$. As a consequence, the import channel of the effect of BI writes as:

$$
\text { Import Channel }=\frac{1-\gamma}{\varepsilon-1} \times \beta_{5}^{s d}=\frac{.5}{2.3-1} \times-0.0125=-0.48 \% .
$$

Given our calibration, we find that the import channel led to $0.48 \%$ increase in consumer welfare through its effect on the price index. As a point of comparison, Berlingieri et al. (2018) estimate in a recent paper that trade agreements implemented by the EU led to an overall decline of $0.24 \%$ in the consumer price

\footnotetext{
${ }^{28}$ This value corresponds to the mean price elasticity of sales in gravity equations (estimated with country fixed-effects) reported in the meta-analysis by Head and Mayer (2014) based on 32 papers and 744 estimates.
} 
index over a 20 year period (1993-2013). ${ }^{29}$ Therefore, while the import channel of broadband internet access might seem moderate, it appears large compared to other policy experiments and accounts for about $25 \%$ of the consumer gains from broadband internet. ${ }^{30}$

\section{Conclusion}

We find broadband expansion to have substantially changed the importing patterns of French small and medium-sized firms. The affected firms increased their overall imports by around a quarter. This was driven by a rise in both the number of source countries and the count of products imported. The rise in imported value exceeded the growth of turnover, resulting in a large increase in import intensity (the imports over sales ratio goes up by about $15 \%$ ).

The first implication of our findings relate to the debate regarding trade vs technology as separate explanations for labor market outcomes. For instance, Autor et al. (2015) argue that trade shocks had more impact than technological shocks on the decline of US manufacturing employment over the 2000's. Our work suggests that it is hard to empirically disentangle the effects of trade from those of technology: a specific instance of technological change, namely broadband internet, has contributed to the trade shocks that this literature typically

\footnotetext{
${ }^{29}$ Note that we use consumer price and consumer welfare interchangeably here. This is an approximation as some of the fixed costs firms need to spend to engage in importing might reduce firm profits. If consumers own the firms, their welfare will be negatively affected as their nominal income from firm ownership will decrease. Therefore reduction in consumer price will be an upper bound for gain in consumer welfare. We consider however this effect to be likely negligible. The model presented here is partial equilibrium in the sense that we ignore how the effect of fixed costs on firms profits might affect consumers' income from firm ownership, we take the price of domestic intermediates as fixed and we do not impose a balanced trade condition.

${ }^{30}$ Our quantification until now has taken the price of domestic intermediate inputs has fixed. In order to aggregate the effect of changes in the import environment onto the overall price level in a general equilibrium setting, we need to specify how the intermediate goods sector operates. A natural way to do this is to postulate a roundabout production whereby firms use a domestic input that is produced using the output of all other firms in the economy (Caliendo and Parro, 2015 , is a recent example using this technology). In this one-sector model this implies that $P=$ $p_{X_{D}}$. Accordingly, substituting equation (17) into (9), we have:

$$
\begin{aligned}
P & =\frac{\sigma-1}{\sigma}\left(\int_{i \in \Omega}\left(\tilde{A}_{i}^{-1} s d_{i}^{\frac{1-\gamma}{\varepsilon-1}}\right)^{1-\sigma} d i\right)^{\frac{1}{1-\sigma}}\left(p_{X_{D}}\right)^{1-\gamma} w^{\gamma} \\
\Rightarrow & P=\frac{\sigma-1}{\sigma}\left(\int_{i \in \Omega}\left(\tilde{A}_{i}^{-1} s d_{i}^{\frac{1-\gamma}{\varepsilon-1}}\right)^{1-\sigma} d i\right)^{\frac{1}{(1-\sigma) \gamma}} w
\end{aligned}
$$

Therefore the aggregate effect is now equal to $1 / \gamma$ times the micro effect, but this does not affect the relative magnitude of the trade channel. With $\gamma=0.5$ for instance, we have a total effect of $3.4 \%$ and an import channel of $0.96 \%$.
} 
takes as given. This interaction is quantitatively large, since we estimate that the rise in import penetration in France over the 1997-2007 period would have been $16 \%$ smaller without broadband internet.

A second implication is that the positive effect of broadband internet on productivity (Akerman et al., 2015) and welfare could be partly driven by the rise in the value and the variety of imported inputs. Under our preferred calibration, our event study estimates suggest that broadband internet resulted in a reduction of $1.7 \%$ in unit costs. The part of those gains that is attributable to enhanced access to foreign inputs (the import channel) is close to $25 \%$ of the total.

Trade and technology affect consumer welfare not only through prices but also through nominal earnings (Borusyak and Jaravel, 2018). Our paper focuses on the former. It is possible, however, that broadband internet induced labor market effects that were differentiated depending on whether firms engaged in international sourcing or not (Koren et al., 2019). Estimating the earning impact of fast internet by skill level and extending the theoretical model to account for richer interactions between purchase of foreign inputs and the skill-content of labor demand appears like an interesting avenue for future research. 


\section{References}

Aghion, P., Bergeaud, A., Lequien, M. and Melitz, M. J. (2018). The impact of exports on innovation: Theory and evidence. Tech. rep., National Bureau of Economic Research.

Akerman, A., GaArder, I. and Mogstad, M. (2015). The Skill Complementarity of Broadband Internet. The Quarterly Journal of Economics, 130 (4), 1781-1824.

-, Leuven, E. and Mogstad, M. (2018). Information frictions, internet and the relationship between distance and trade. mimeo, p. 48.

Amiti, M. and Konings, J. (2007). Trade liberalization, intermediate inputs, and productivity: Evidence from indonesia. American Economic Review, 97 (5), 16111638.

Andrews, D., Nicoletti, G. and Timiliotis, C. (2018). Going digital: What determines technology diffusion among firms? Tech. rep.

Antras, P., FORT, T. C. and TintelnOt, F. (2017). The margins of global sourcing: Theory and evidence from us firms. American Economic Review, 107 (9), 2514-64.

ARCEP (2002). L'accés haut débit via l'ADSL : historique des décisions de l'ART et de l'ARCEP. Tech. rep.

- (2016). Etude sur les équipements et usages des PME et ETI. Tech. rep.

Arkolakis, C., Costinot, A. and Rodríguez-Clare, A. (2012). New trade models, same old gains? American Economic Review, 102 (1), 94-130.

Autor, D., Dorn, D., Hanson, G. H., Pisano, G. and SHu, P. (2016a). Foreign competition and domestic innovation: Evidence from US patents. Tech. rep., National Bureau of Economic Research.

Autor, D. H. (2003). Outsourcing at will: The contribution of unjust dismissal doctrine to the growth of employment outsourcing. Journal of labor economics, $21(1), 1-42$.

—, DORN, D. and HANSON, G. H. (2013). The china syndrome: Local labor market effects of import competition in the united states. American Economic Review, 103 (6), 2121-68. 
- , - and - (2015). Untangling trade and technology: Evidence from local labour markets. The Economic Journal, 125 (584), 621-646.

- , - and - (2016b). The china shock: Learning from labor-market adjustment to large changes in trade. Annual Review of Economics, 8, 205-240.

BADRÉ, D. (2007). Tarification de l'usage d'internet: Question écrite n 10755. Senat, 11eme législature.

BALDWIN, R. (2016). The great convergence. Harvard University Press.

BALDWIN, R. E. (2009). The great trade collapse: Causes, consequences and prospects. Cepr.

BARbero, J. and RodrigueZ-Crespo, E. (2018). The effect of broadband on eu trade: a regional spatial approach. The World Economy.

Bergounhon, F., Lenoir, C. and Mejean, I. (2018). A guideline to french firmlevel trade data. mimeo Polytechnique.

BERlingieRI, G., BREINLICH, H. and Dhingra, S. (2018). The impact of trade agreements on consumer welfare-evidence from the eu common external trade policy. Journal of the European Economic Association, 16 (6), 1881-1928.

Bertrand, M., Duflo, E. and Mullainathan, S. (2004). How much should we trust differences-in-differences estimates? The Quarterly journal of economics, 119 (1), 249-275.

BertscheK, I., Wolfgang, B., Kai, H., Benedikt, K. and Niebel, T. (2015). The economic impacts of broadband internet: A survey. Review of Network Economics, 14 (4), 201-227.

Blaum, J., Lelarge, C. and Peters, M. (2018). The gains from input trade with heterogeneous importers. American Economic Journal: Macroeconomics, 10 (4), 77-127.

Bloom, N., Draca, M. and Van Reenen, J. (2016). Trade induced technical change? the impact of chinese imports on innovation, IT and productivity. The Review of Economic Studies, 83 (1), 87-117.

BORUSYAK, K. and JARAVEL, X. (2017). Revisiting event study designs with an application to the estimation of the marginal propensity to consume. mimeo, p. 33. 
— and - (2018). The distributional effects of trade: Theory and evidence from the united states. Available at SSRN 3269579.

BRODA, C. and WEINSTEIN, D. E. (2006). Globalization and the gains from variety. The Quarterly journal of economics, 121 (2), 541-585.

CALIENDO, L. and PARRO, F. (2015). Estimates of the trade and welfare effects of nafta. The Review of Economic Studies, 82 (1), 1-44.

ChetTY, R. (2009). Sufficient statistics for welfare analysis: A bridge between structural and reduced-form methods. Annu. Rev. Econ., 1 (1), 451-488.

-, LoOney, A. and Kroft, K. (2009). Salience and taxation: Theory and evidence. American economic review, 99 (4), 1145-77.

Clarke, G. R. and Wallsten, S. J. (2006). Has the internet increased trade? developed and developing country evidence. Economic Inquiry, 44 (3), 465-484.

Cohen, D., Garibaldi, P. and ScarpetTA, S. (2004). The ICT revolution: Productivity differences and the digital divide. Oxford University Press.

Dauth, W., Findeisen, S. and SuedeKum, J. (2014). The rise of the east and the far east: German labor markets and trade integration. Journal of the European Economic Association, 12 (6), 1643-1675.

DeStefano, T., KNeller, R. and Timmis, J. (2018). Broadband infrastructure, ict use and firm performance: Evidence for uk firms. Journal of Economic Behavior \& Organization, 155, 110-139.

EAton, J. and Kortum, S. (2001). Trade in capital goods. European Economic Review, 45 (7), 1195-1235.

- , - and Kramarz, F. (2011). An anatomy of international trade: Evidence from french firms. Econometrica, 79 (5), 1453-1498.

Feenstra, R. C. and Weinstein, D. E. (2017). Globalization, markups, and us welfare. Journal of Political Economy, 125 (4), 1040-1074.

FORT, T. C. (2017). Technology and production fragmentation: Domestic versus foreign sourcing. The Review of Economic Studies, 84 (2), 650-687.

-, Pierce, J. R. and SchotT, P. K. (2018). New perspectives on the decline of us manufacturing employment. Journal of Economic Perspectives, 32 (2), 47-72. 
GoOdman-BAcon, A. (2018). Difference-in-Differences with Variation in Treatment Timing. Tech. rep., National Bureau of Economic Research.

Gopinath, G. and Neiman, B. (2014). Trade adjustment and productivity in large crises. American Economic Review, 104 (3), 793-831.

Gross, T., NotOWIDIGDO, M. J. and WANG, J. (2018). The marginal propensity to consume over the business cycle.

HALPERN, L., KOREN, M. and SzEIDL, A. (2015). Imported inputs and productivity. American Economic Review, 105 (12), 3660-3703.

HEAD, K. and MAYER, T. (2014). Gravity equations: Workhorse, toolkit, and cookbook. In Handbook of international economics, vol. 4, Elsevier, pp. 131-195.

HJORT, J. and POUlsen, J. (2018). The arrival of fast internet and employment in africa. American Economic Review.

HoungbonOn, G. V. and LiAnG, J. (2017). Broadband internet and income inequality.

- and - (2018). The impact of broadband internet on employment in france. Available at SSRN 3112182.

JuhÁsz, R. and STEINWENDER, C. (2018). Spinning the web: The impact of ICT on trade in intermediates and technology diffusion. Tech. rep., National Bureau of Economic Research.

KNELler, R. and Timmis, J. (2016). Ict and exporting: The effects of broadband on the extensive margin of business service exports. Review of International Economics, 24 (4), 757-796.

Koren, M., Csillag, M. and KÖLlO, J. (2019). Machines and machinists: Importing skill-biased technology. mimeo.

KOVAK, B. K. (2013). Regional effects of trade reform: What is the correct measure of liberalization? American Economic Review, 103 (5), 1960-76.

LE GALL, F. (2007). ADSL : France Télécom a équipé tous les NRA. Tech. rep.

Mayer, T., Melitz, M. J. and Ottaviano, G. I. (2014). Market size, competition, and the product mix of exporters. American Economic Review, 104 (2), 495-536. 
MuendLeR, M.-A. (2017). Trade, technology, and prosperity: An account of evidence from a labor-market perspective. Tech. rep., WTO Staff Working Paper.

Portugal-Perez, A. and Wilson, J. S. (2012). Export performance and trade facilitation reform: Hard and soft infrastructure. World development, 40 (7), 1295-1307.

SANDOZ, C. (2017). Input prices, allocation of resources and tfp growth: Evidence from chinese imports in france. Job market paper, PSE.

SCHMidheiny, K. and Siegloch, S. (2019). On event study designs and distributed-lag models: Equivalence, generalization and practical implications.

SÉNAT (2002). Le bilan de la loi n 96-659 de réglementation des télécommunications. RAPPORT D'INFORMATION DU SÉNAT.

Shu, P. and SteInWENDer, C. (2019). The impact of trade liberalization on firm productivity and innovation. Innovation Policy and the Economy, 19 (1), 39-68.

STEINWENDER, C. (2018). Real effects of information frictions: When the states and the kingdom became united. American Economic Review, 108 (3), 657-96.

Telecom, F. (2003). Conférence de presse du 10 juin 2003 "Internet Haut Débit pour tous : France Télécom s'engage". Tech. rep.

Topalova, P. (2010). Factor immobility and regional impacts of trade liberalization: Evidence on poverty from india. American Economic Journal: Applied Economics, 2 (4), 1-41.

— and KhandelWAL, A. (2011). Trade liberalization and firm productivity: The case of india. Review of economics and statistics, 93 (3), 995-1009.

TRegouet, R. (2001). Question écrite n. 30844 (sénat, 01/02/2001). Senat. 


\section{A Tables and figures}

\section{A.1 Baseline tables}

Table A1: Specification checks for main specification: $\ln ($ value of imports)

\begin{tabular}{|c|c|c|c|c|c|c|c|}
\hline & \multicolumn{7}{|c|}{ Ln (Values of Imports) } \\
\hline & (1) & (2) & (3) & (4) & (5) & (6) & (7) \\
\hline \multirow[t]{2}{*}{$\mathbb{1}\{d=-5\}$} & -0.019 & -0.021 & -0.026 & -0.008 & -0.024 & & \\
\hline & $(0.015)$ & $(0.015)$ & $(0.016)$ & $(0.020)$ & $(0.017)$ & & \\
\hline \multirow[t]{2}{*}{$\mathbb{1}\{d=-4\}$} & -0.006 & -0.008 & -0.016 & 0.002 & -0.020 & & \\
\hline & $(0.014)$ & $(0.015)$ & $(0.015)$ & $(0.020)$ & $(0.016)$ & & \\
\hline \multirow[t]{2}{*}{$\mathbb{1}\{d=-3\}$} & -0.008 & -0.014 & -0.023 & -0.013 & -0.025 & & \\
\hline & $(0.012)$ & $(0.013)$ & $(0.014)$ & $(0.017)$ & $(0.015)$ & & \\
\hline \multirow[t]{2}{*}{$\mathbb{1}\{d=-2\}$} & -0.012 & -0.016 & $-0.022^{*}$ & -0.017 & -0.020 & & \\
\hline & $(0.012)$ & $(0.013)$ & $(0.013)$ & $(0.013)$ & $(0.013)$ & & \\
\hline \multirow{2}{*}{$\mathbb{1}\{d=0\}$} & 0.005 & 0.009 & 0.018 & 0.013 & $0.025^{*}$ & 0.016 & $0.027^{*}$ \\
\hline & $(0.012)$ & $(0.013)$ & $(0.013)$ & $(0.013)$ & $(0.013)$ & $(0.016)$ & $(0.016)$ \\
\hline \multirow[t]{2}{*}{$\mathbb{1}\{d=1\}$} & 0.030 & $0.039^{* *}$ & $0.060^{* * *}$ & $0.047^{* *}$ & $0.062^{* * *}$ & $0.046^{* *}$ & $0.067^{* * *}$ \\
\hline & $(0.018)$ & $(0.019)$ & $(0.020)$ & $(0.021)$ & $(0.020)$ & $(0.022)$ & $(0.022)$ \\
\hline \multirow[t]{2}{*}{$\mathbb{1}\{d=2\}$} & $0.075^{* * *}$ & $0.092^{* * *}$ & $0.125^{* * *}$ & $0.103^{* * *}$ & $0.135^{* * *}$ & $0.097^{* * *}$ & $0.130^{* * *}$ \\
\hline & $(0.024)$ & $(0.025)$ & $(0.028)$ & $(0.030)$ & $(0.029)$ & $(0.027)$ & $(0.029)$ \\
\hline \multirow[t]{2}{*}{$\mathbb{1}\{d=3\}$} & $0.082^{* * *}$ & $0.110^{* * *}$ & $0.158^{* * *}$ & $0.128^{* * *}$ & $0.163^{* * *}$ & $0.114^{* * *}$ & $0.161^{* * *}$ \\
\hline & $(0.030)$ & $(0.032)$ & $(0.038)$ & $(0.041)$ & $(0.039)$ & $(0.036)$ & $(0.039)$ \\
\hline \multirow[t]{2}{*}{$\mathbb{1}\{d=4\}$} & $0.099^{* * *}$ & $0.143^{* * *}$ & $0.209^{* * *}$ & $0.170^{* * *}$ & $0.208^{* * *}$ & $0.146^{* * *}$ & $0.211^{* * *}$ \\
\hline & $(0.036)$ & $(0.038)$ & $(0.046)$ & $(0.050)$ & $(0.048)$ & $(0.041)$ & $(0.048)$ \\
\hline \multirow[t]{2}{*}{$\mathbb{1}\{d=5\}$} & $0.107^{* *}$ & $0.162^{* * *}$ & $0.249 * * *$ & $0.201^{* * *}$ & $0.245^{* * *}$ & $0.165^{* * *}$ & $0.250^{* * *}$ \\
\hline & $(0.048)$ & $(0.050)$ & $(0.062)$ & $(0.065)$ & $(0.062)$ & $(0.054)$ & $(0.064)$ \\
\hline Year FE & Yes & No & No & No & No & No & No \\
\hline Year x Dep. FE & No & Yes & Yes & Yes & No & Yes & Yes \\
\hline Year $x$ ZE FE & No & No & No & No & Yes & No & No \\
\hline City FE & Yes & Yes & Yes & Yes & Yes & Yes & Yes \\
\hline Density controls & No & No & Yes & Yes & Yes & No & Yes \\
\hline Fiscal + Sector + Educ. controls & No & No & No & Yes & No & No & No \\
\hline Spec. & $\mathrm{D}$ & $\mathrm{D}$ & $\mathrm{D}$ & $\mathrm{D}$ & $\mathrm{D}$ & SD & SD \\
\hline Observations & 103015 & 103015 & 103001 & 96620 & 102991 & 103015 & 103001 \\
\hline
\end{tabular}

Notes : This table presents event-study estimates based on Equations (2) (columns 1 to 5) and (3) (columns 6 and 7). Robust standard errors clustered at the département level are presented in brackets. ${ }^{*} p<0.1,{ }^{* *} p<0.05,^{* * *}$ $\mathrm{p}<0.01$. Estimates are plotted in Figure 3, see the figure notes for more details on the controls. 
Table A2: Specification checks for main specification: asinh(value of imports)

\begin{tabular}{|c|c|c|c|c|c|c|c|}
\hline & \multicolumn{7}{|c|}{ Asinh (Values of Imports) } \\
\hline & (1) & (2) & (3) & $(4)$ & $(5)$ & (6) & (7) \\
\hline $\mathbb{1}\{d=-5\}$ & $\begin{array}{c}-0.014 \\
(0.016)\end{array}$ & $\begin{array}{c}-0.017 \\
(0.017)\end{array}$ & $\begin{array}{c}-0.023 \\
(0.017)\end{array}$ & $\begin{array}{c}-0.013 \\
(0.021)\end{array}$ & $\begin{array}{c}-0.026 \\
(0.018)\end{array}$ & & \\
\hline $\mathbb{1}\{d=-4\}$ & $\begin{array}{c}-0.005 \\
(0.021)\end{array}$ & $\begin{array}{c}-0.011 \\
(0.022)\end{array}$ & $\begin{array}{l}-0.020 \\
(0.022)\end{array}$ & $\begin{array}{c}0.004 \\
(0.027)\end{array}$ & $\begin{array}{l}-0.016 \\
(0.022)\end{array}$ & & \\
\hline $\mathbb{1}\{d=-3\}$ & $\begin{array}{c}-0.001 \\
(0.018)\end{array}$ & $\begin{array}{c}-0.008 \\
(0.019)\end{array}$ & $\begin{array}{c}-0.018 \\
(0.020)\end{array}$ & $\begin{array}{c}-0.003 \\
(0.023)\end{array}$ & $\begin{array}{l}-0.024 \\
(0.021)\end{array}$ & & \\
\hline $\mathbb{1}\{d=-2\}$ & $\begin{array}{c}0.015 \\
(0.014)\end{array}$ & $\begin{array}{c}0.014 \\
(0.015)\end{array}$ & $\begin{array}{c}0.008 \\
(0.015)\end{array}$ & $\begin{array}{c}0.013 \\
(0.017)\end{array}$ & $\begin{array}{c}0.011 \\
(0.016)\end{array}$ & & \\
\hline $\mathbb{1}\{d=0\}$ & $\begin{array}{c}0.039 * \\
(0.022)\end{array}$ & $\begin{array}{c}0.043^{*} \\
(0.022)\end{array}$ & $\begin{array}{l}0.050^{* *} \\
(0.023)\end{array}$ & $\begin{array}{l}0.051^{* *} \\
(0.023)\end{array}$ & $\begin{array}{l}0.051^{* *} \\
(0.022)\end{array}$ & $\begin{array}{c}0.036 \\
(0.023)\end{array}$ & $\begin{array}{c}0.047^{*} \\
(0.024)\end{array}$ \\
\hline $\mathbb{1}\{d=1\}$ & $\begin{array}{l}0.063^{* *} \\
(0.030)\end{array}$ & $\begin{array}{c}0.066^{* *} \\
(0.030)\end{array}$ & $\begin{array}{l}0.082^{* *} \\
(0.032)\end{array}$ & $\begin{array}{l}0.081^{* *} \\
(0.033)\end{array}$ & $\begin{array}{l}0.077^{* *} \\
(0.033)\end{array}$ & $\begin{array}{c}0.057^{*} \\
(0.031)\end{array}$ & $\begin{array}{l}0.074^{* *} \\
(0.033)\end{array}$ \\
\hline $\mathbb{1}\{d=2\}$ & $\begin{array}{l}0.111^{* * *} \\
(0.040)\end{array}$ & $\begin{array}{l}0.123^{* * *} \\
(0.040)\end{array}$ & $\begin{array}{l}0.144^{* * *} \\
(0.043)\end{array}$ & $\begin{array}{l}0.142^{* * * *} \\
(0.045)\end{array}$ & $\begin{array}{l}0.141^{* * *} \\
(0.044)\end{array}$ & $\begin{array}{l}0.110^{* * *} \\
(0.041)\end{array}$ & $\begin{array}{l}0.133^{* * *} \\
(0.045)\end{array}$ \\
\hline $\mathbb{1}\{d=3\}$ & $\begin{array}{l}0.155^{* * *} \\
(0.052)\end{array}$ & $\begin{array}{c}0.173^{* * *} \\
(0.052)\end{array}$ & $\begin{array}{l}0.199 * * * \\
(0.058)\end{array}$ & $\begin{array}{l}0.195^{* * *} \\
(0.060)\end{array}$ & $\begin{array}{l}0.200^{* * *} \\
(0.061)\end{array}$ & $\begin{array}{l}0.157^{* * *} \\
(0.053)\end{array}$ & $\begin{array}{l}0.185^{* * *} \\
(0.060)\end{array}$ \\
\hline $\mathbb{1}\{d=4\}$ & $\begin{array}{l}0.218^{* * * *} \\
(0.063)\end{array}$ & $\begin{array}{l}0.249^{* * *} \\
(0.067)\end{array}$ & $\begin{array}{l}0.281^{* * *} \\
(0.076)\end{array}$ & $\begin{array}{l}0.266^{* * * *} \\
(0.080)\end{array}$ & $\begin{array}{l}0.265^{* * * *} \\
(0.079)\end{array}$ & $\begin{array}{l}0.231^{* * *} \\
(0.068)\end{array}$ & $\begin{array}{l}0.263^{* * *} \\
(0.077)\end{array}$ \\
\hline $\mathbb{1}\{d=5\}$ & $\begin{array}{l}0.305^{* * *} \\
(0.087)\end{array}$ & $\begin{array}{l}0.340^{* * *} \\
(0.088)\end{array}$ & $\begin{array}{l}0.377^{* * *} \\
(0.097)\end{array}$ & $\begin{array}{l}0.349^{* * * *} \\
(0.100)\end{array}$ & $\begin{array}{l}0.358^{* * * *} \\
(0.099)\end{array}$ & $\begin{array}{l}0.319^{* * *} \\
(0.088)\end{array}$ & $\begin{array}{l}0.357^{* * *} \\
(0.098)\end{array}$ \\
\hline Year FE & Yes & No & No & No & No & No & No \\
\hline Year x Dep. FE & No & Yes & Yes & Yes & No & Yes & Yes \\
\hline Year $x$ ZE FE & No & No & No & No & Yes & No & No \\
\hline City FE & Yes & Yes & Yes & Yes & Yes & Yes & Yes \\
\hline Density controls & No & No & Yes & Yes & Yes & No & Yes \\
\hline Fiscal + Sector + Educ. controls & No & No & No & Yes & No & No & No \\
\hline Spec. & $\mathrm{D}$ & $\mathrm{D}$ & $\mathrm{D}$ & $\mathrm{D}$ & $\mathrm{D}$ & SD & SD \\
\hline Observations & 315161 & 315161 & 314953 & 293634 & 314952 & 315161 & 314953 \\
\hline
\end{tabular}

NOTES : This table presents event-study estimates based on Equations (2) (columns 1 to 5) and (3) (columns 6 and 7). Robust standard errors clustered at the département level are presented in brackets. ${ }^{*} \mathrm{p}<0.1,{ }^{* *} \mathrm{p}<0.05,{ }^{* * *}$ $\mathrm{p}<0.01$. Estimates are plotted in Figure 3, see the figure notes for more details on the controls. 


\section{A.2 Pseudo first-stage}

Figure A1: The evolution of continuous measure of broadband coverage $\left(\widetilde{Z}_{i t}\right)$ around the (discrete) year of the largest increase in $\widetilde{Z}_{i t}\left(t_{0 i}\right)$.

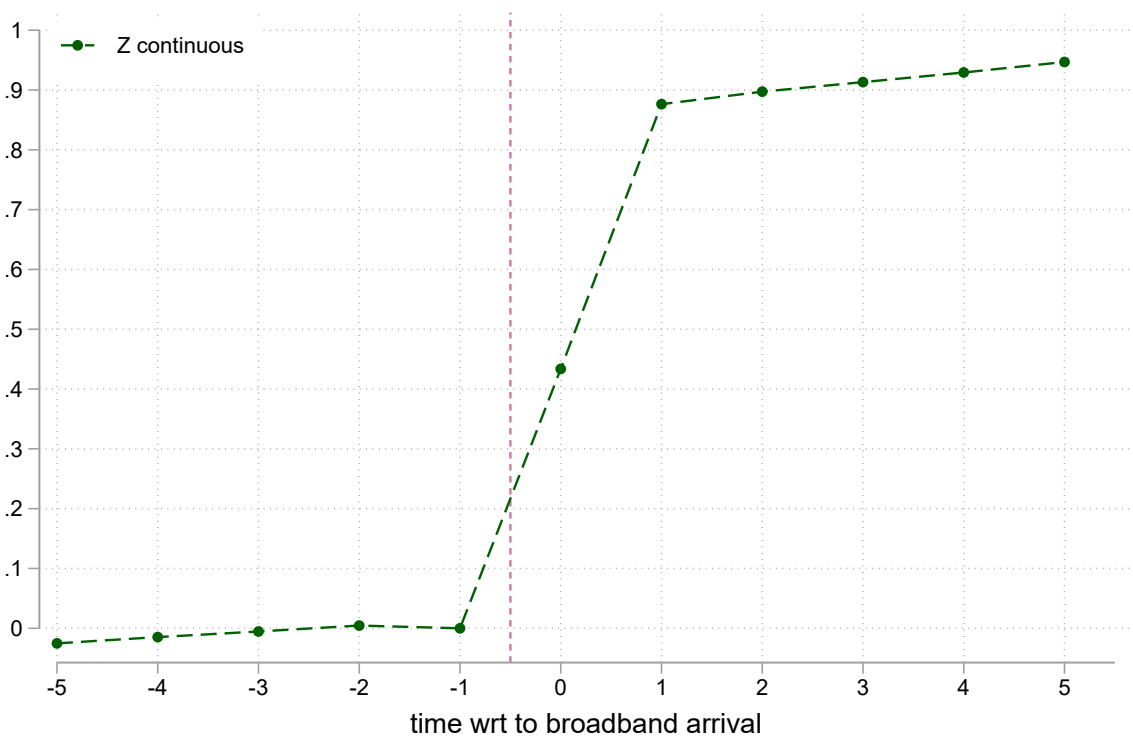

NOTES: This figure plots estimates from regression of $\widetilde{Z}_{i t}$ on set of time to broadband expansion dummies with year fixed effect.

The time at -1 is normalized to $0.95 \%$ confidence intervals are displayed (but graphically invisible due to their small size) The sample in clude all cities with a positive trade flow (import). 


\section{A.3 Robustness checks}

Sensitivity with respect to binning pre-treatment periods

This appendix presents results based on the following specification:

$$
Y_{i t}=\beta_{d_{0}} \times \mathbb{1}\left\{t-t_{0 i} \leq-4\right\}+\sum_{\substack{d=-d_{0}+1 \\ d \neq-1}}^{d_{1}} \beta_{d} \times \mathbb{1}\left\{d+t_{0 i}=t\right\}+\mathbf{x}_{i t}^{\prime} \delta+\alpha_{i}+\psi_{d(i), t}+\varepsilon_{i t}
$$

$t_{0 i}$ refers to the city-specific arrival year of broadband internet. Periods relative to broadband expansion are index by $d$. In this specification, the coefficients for $d \leq d_{0}$ are constrained to be equal (they are binned together in the terminology of Schmidheiny and Siegloch (2019)). More specifically, we consider observations with $d \in\{-6,5\}$ and we set $d_{0}=4$. 
Table A3: Specification Check: $\ln ($ value of imports) , binning $d \in\{-6,-5,-4\}$

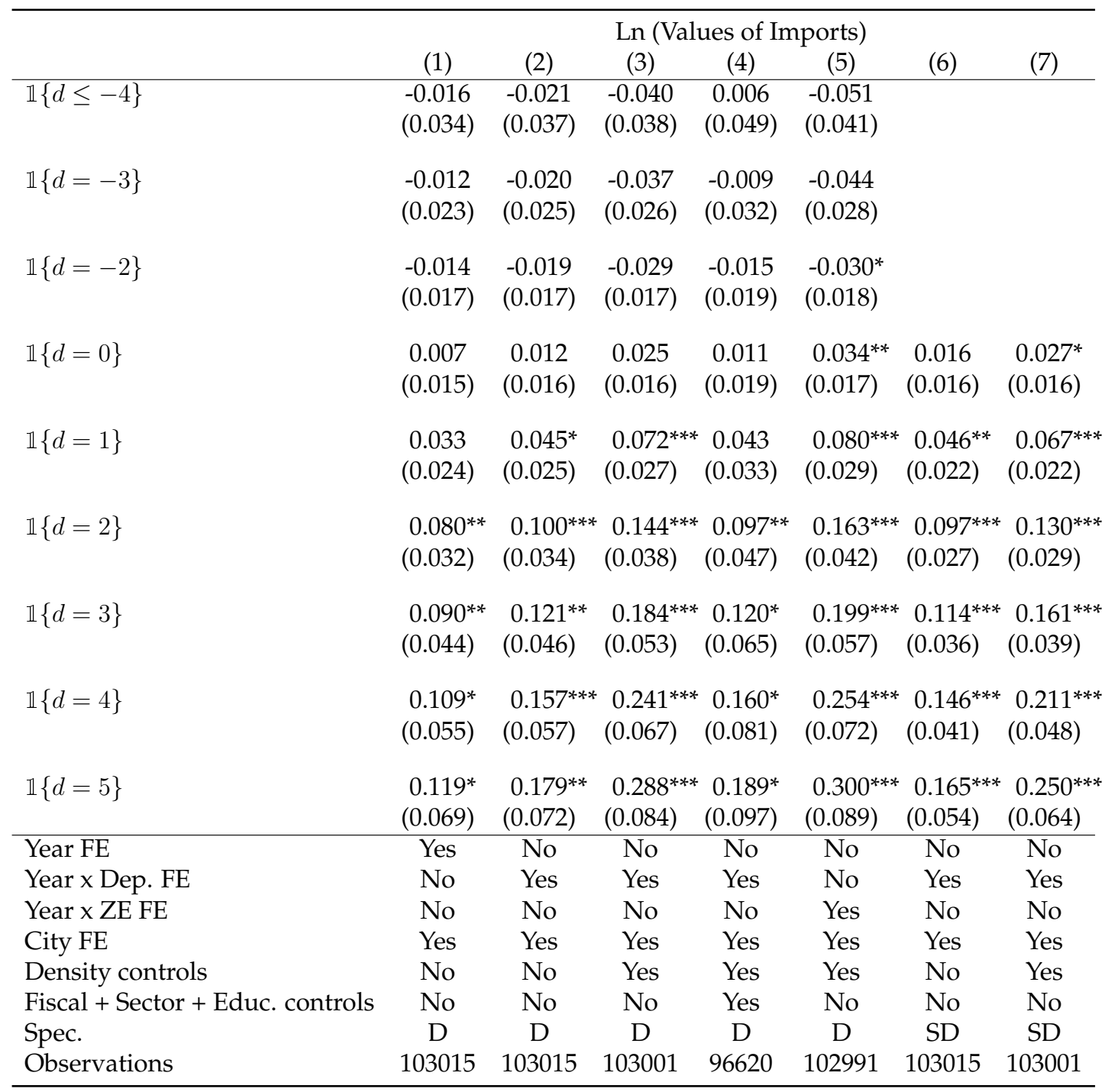

Notes : This table presents event-study estimates based on Equations (21)) (columns 1 to 5) and (3) (columns 6 and 7). Observations up to 6 year before and 5 year after broadband expansion are included in the estimating sample and the indicator variables for periods -6 to -4 are binned together. Robust standard errors clustered at the département level are presented in brackets. ${ }^{*} \mathrm{p}<0.1,{ }^{* *} \mathrm{p}<0.05,{ }^{* * *} \mathrm{p}<0.01$. 
Table A4: Static panel-fixed effect model: 1997-2003

\begin{tabular}{lcccccc}
\hline & \multicolumn{5}{c}{ Ln (Values of Imports) } \\
& $(1)$ & $(2)$ & $(3)$ & $(4)$ & $(5)$ & $(6)$ \\
\hline ADSL access $(\widetilde{Z})$ & 0.034 & $0.051^{* *}$ & $0.066^{* *}$ & $0.050^{*}$ & $0.057^{* *}$ & $0.070^{* * *}$ \\
& $(0.025)$ & $(0.025)$ & $(0.025)$ & $(0.026)$ & $(0.026)$ & $(0.026)$ \\
\hline Year FE & Yes & No & No & No & No & No \\
Year x Dep. FE & No & Yes & Yes & Yes & No & No \\
Year x ZE FE & No & No & No & No & Yes & Yes \\
City FE & Yes & Yes & Yes & Yes & Yes & Yes \\
Density controls & No & No & Yes & Yes & No & Yes \\
Fiscal + Sector + Educ. controls & No & No & No & Yes & No & No \\
Spec. & S & S & S & S & S & S \\
Observations & 65175 & 65175 & 65175 & 65167 & 65167 & 65167 \\
\hline
\end{tabular}

NOTES : This table presents simple static event-study estimates based on a static version of Equations. The explanatory variable of interest Broadband Internet access is the continuous measure of broadband access in city $i$ and year $t$ defined as a time-weighted percentage of area covered in city $i$. This variable is formally defined above. Robust standard errors clustered at the province (département)level are presented in brackets. ${ }^{*} \mathrm{p}<0.1,{ }^{* *} \mathrm{p}<0.05,{ }^{* * *} \mathrm{p}<0.01$. Estimates are plotted in Figure 3, see the figure notes for more details on the controls. 


\section{A.4 Explaining internet coverage : table}

Table A5: Explaining variation in internet coverage: full panel regressions

\begin{tabular}{|c|c|c|c|c|c|c|}
\hline & $\begin{array}{c}(1) \\
\text { Covariates }\end{array}$ & $\begin{array}{c}(2) \\
\text { Twoway FE }\end{array}$ & $\begin{array}{c}\text { (3) } \\
\text { (2)+density }\end{array}$ & $\begin{array}{c}(4) \\
\text { (2)+indus. }\end{array}$ & $\begin{array}{c}(5) \\
(2)+\text { trade. }\end{array}$ & $\begin{array}{c}(6) \\
(2)+\text { all cova. }\end{array}$ \\
\hline Lagged: share_primary & $\begin{array}{l}-0.0206 \\
(-1.27)\end{array}$ & & & $\begin{array}{c}-0.0702 \\
(-1.00)\end{array}$ & & $\begin{array}{c}-0.0932 \\
(-1.28)\end{array}$ \\
\hline Lagged: share_construction & $\begin{array}{c}-0.0158 \\
(-0.47)\end{array}$ & & & $\begin{array}{l}-0.198 \\
(-1.66)\end{array}$ & & $\begin{array}{l}-0.102 \\
(-0.96)\end{array}$ \\
\hline Lagged: share_auto & $\begin{array}{l}0.0301^{* * *} \\
(7.01)\end{array}$ & & & $\begin{array}{c}-0.0185 \\
(-0.98)\end{array}$ & & $\begin{array}{c}-0.0154 \\
(-0.83)\end{array}$ \\
\hline Lagged: share_transport & $\begin{array}{l}0.0370^{* * *} \\
(7.74)\end{array}$ & & & $\begin{array}{l}0.0131 \\
(0.74)\end{array}$ & & $\begin{array}{c}-0.00123 \\
(-0.07)\end{array}$ \\
\hline Lagged: share_hotel & $\begin{array}{c}0.0136 \\
(1.78)\end{array}$ & & & $\begin{array}{c}-0.0156 \\
(-0.42)\end{array}$ & & $\begin{array}{c}-0.0000880 \\
(-0.00)\end{array}$ \\
\hline Lagged: share_telecom & $\begin{array}{l}0.0279^{* * *} \\
(4.02)\end{array}$ & & & $\begin{array}{l}0.0267 \\
(1.14)\end{array}$ & & $\begin{array}{c}0.0175 \\
(0.75)\end{array}$ \\
\hline Lagged: share_service_pro & $\begin{array}{l}0.0278^{* * *} \\
(8.24)\end{array}$ & & & $\begin{array}{c}-0.0148 \\
(-0.86)\end{array}$ & & $\begin{array}{c}-0.0292 \\
(-1.80)\end{array}$ \\
\hline Lagged: share_service_pers & $\begin{array}{l}0.0372^{* * *} \\
(3.60)\end{array}$ & & & $\begin{array}{l}0.0256 \\
(0.72)\end{array}$ & & $\begin{array}{l}0.0108 \\
(0.29)\end{array}$ \\
\hline Lagged $\Delta$ share_primary & $\begin{array}{c}-0.0238 \\
(-0.39)\end{array}$ & & & $\begin{array}{c}0.0240 \\
(0.42)\end{array}$ & & $\begin{array}{c}0.0175 \\
(0.31)\end{array}$ \\
\hline Lagged $\Delta$ share_construction & $\begin{array}{l}-0.111 \\
(-1.51)\end{array}$ & & & $\begin{array}{c}0.0852 \\
(1.27)\end{array}$ & & $\begin{array}{l}0.0528 \\
(0.85)\end{array}$ \\
\hline Lagged $\Delta$ share_auto & $\begin{array}{c}-0.00375 \\
(-0.25)\end{array}$ & & & $\begin{array}{l}0.0104 \\
(0.72)\end{array}$ & & $\begin{array}{c}0.00857 \\
(0.60)\end{array}$ \\
\hline Lagged $\Delta$ share_transport & $\begin{array}{c}-0.0142 \\
(-0.82)\end{array}$ & & & $\begin{array}{c}-0.00782 \\
(-0.48)\end{array}$ & & $\begin{array}{c}-0.00356 \\
(-0.22)\end{array}$ \\
\hline Lagged $\Delta$ share_hotel & $\begin{array}{c}-0.0507 \\
(-1.93)\end{array}$ & & & $\begin{array}{c}-0.0183 \\
(-0.72)\end{array}$ & & $\begin{array}{c}-0.0219 \\
(-0.89)\end{array}$ \\
\hline Lagged $\Delta$ share_telecom & $\begin{array}{c}-0.00426 \\
(-0.18)\end{array}$ & & & $\begin{array}{l}-0.0165 \\
(-0.90)\end{array}$ & & $\begin{array}{c}-0.00775 \\
(-0.43)\end{array}$ \\
\hline Lagged $\Delta$ share_service_pro & $\begin{array}{c}-0.0248 \\
(-1.91)\end{array}$ & & & $\begin{array}{c}-0.00740 \\
(-0.62)\end{array}$ & & $\begin{array}{c}0.0108 \\
(0.90)\end{array}$ \\
\hline Lagged $\Delta$ share_service_pers & $\begin{array}{c}-0.0384 \\
(-1.40)\end{array}$ & & & $\begin{array}{c}-0.0169 \\
(-0.61)\end{array}$ & & $\begin{array}{c}-0.0218 \\
(-0.80)\end{array}$ \\
\hline Lagged asinhn_flowsM & $\begin{array}{l}0.00728^{* * *} \\
(8.04)\end{array}$ & & & & $\begin{array}{c}-0.00511^{*} \\
(-2.44)\end{array}$ & $\begin{array}{c}-0.00184 \\
(-0.92)\end{array}$ \\
\hline Lagged asinhvaleurM & $\begin{array}{c}0.000263 \\
(0.95)\end{array}$ & & & & $\begin{array}{c}0.000680 \\
(1.38)\end{array}$ & $\begin{array}{c}-0.0000708 \\
(-0.15)\end{array}$ \\
\hline Lagged $\Delta$ asinhn_flowsM & $\begin{array}{c}-0.00278 \\
(-1.74)\end{array}$ & & & & $\begin{array}{c}0.00104 \\
(0.70)\end{array}$ & $\begin{array}{c}0.000209 \\
(0.15)\end{array}$ \\
\hline Lagged $\Delta$ asinhvaleurM & $\begin{array}{c}0.0000509 \\
(0.15)\end{array}$ & & & & $\begin{array}{c}0.0000843 \\
(0.28)\end{array}$ & $\begin{array}{c}0.000381 \\
(1.33)\end{array}$ \\
\hline year=1999 × Ln Density 1999 & $\begin{array}{l}-0.0417^{* * *} \\
(-45.67)\end{array}$ & & $\begin{array}{l}-0.0357^{* * *} \\
(-6.92)\end{array}$ & & & $\begin{array}{l}0 \\
(.)\end{array}$ \\
\hline year=2000 × Ln Density 1999 & $\begin{array}{l}-0.0274^{* * *} \\
(-29.91)\end{array}$ & & $\begin{array}{l}0 \\
(.)\end{array}$ & & & $\begin{array}{l}0.0358^{* * *} \\
(6.95)\end{array}$ \\
\hline year=2001 × Ln Density 1999 & $\begin{array}{l}0.0117^{* * *} \\
(12.74)\end{array}$ & & $\begin{array}{l}0.0785^{* * *} \\
(15.51)\end{array}$ & & & $\begin{array}{l}0.114^{* * *} \\
(26.32)\end{array}$ \\
\hline year=2002 × Ln Density 1999 & $\begin{array}{l}0.0487^{* * *} \\
(53.15)\end{array}$ & & $\begin{array}{l}0.132^{* * *} \\
(17.32)\end{array}$ & & & $\begin{array}{l}0.168^{* * *} \\
(34.48)\end{array}$ \\
\hline year=2003 × Ln Density 1999 & $\begin{array}{l}0.0831^{* * *} \\
(91.00)\end{array}$ & & $\begin{array}{l}0.140^{* * *} \\
(13.20)\end{array}$ & & & $\begin{array}{l}0.175^{* * *} \\
(26.05)\end{array}$ \\
\hline year=2004 × Ln Density 1999 & $\begin{array}{l}0.123^{* * *} \\
(134.21)\end{array}$ & & $\begin{array}{l}0.113^{* * *} \\
(9.14)\end{array}$ & & & $\begin{array}{l}0.149^{* * *} \\
(17.57)\end{array}$ \\
\hline year=2005 × Ln Density 1999 & $\begin{array}{l}0.161^{* * * *} \\
(175.68)\end{array}$ & & $\begin{array}{l}0.0566^{* * *} \\
(4.98)\end{array}$ & & & $\begin{array}{l}0.0923^{* * *} \\
(12.38)\end{array}$ \\
\hline year=2006 × Ln Density 1999 & $\begin{array}{l}0.185^{* * *} \\
(200.79)\end{array}$ & & $\begin{array}{c}0.00315 \\
(0.37)\end{array}$ & & & $\begin{array}{l}0.0388^{* * *} \\
(8.27)\end{array}$ \\
\hline year=2007 × Ln Density 1999 & $\begin{array}{l}0.193^{* * *} \\
(209.08)\end{array}$ & & $\begin{array}{l}-0.0177^{*} \\
(-2.57)\end{array}$ & & & $\begin{array}{l}0.0180^{* * *} \\
(6.00)\end{array}$ \\
\hline$R^{2}$ & 0.563 & 0.786 & 0.812 & 0.786 & 0.786 & 0.812 \\
\hline
\end{tabular}

NOTES : This table presents panel regression estimates based on equation (4). ${ }^{*} \mathrm{p}<0.1,{ }^{* *} \mathrm{p}<0.05,{ }^{* * *} \mathrm{p}<0.01$ 


\section{B Data appendix}

\section{B.1 Description of the datasets}

Here we present in some more details the datatsets used in the analysis:

1. DADS: employment at the establishment level: The annual social data declaration (DADS) files contain information on each salaried contract for all firms of the competitive sector. Crucially, the place of work is documented at the city level. We use a version of this dataset that is aggregated at the establishment-level and allows us to locate firms and choose singlecity firms. The firm identifier is identical to the one present in the customs and balance sheet data thus allowing us to localize the importing and economic performance of firms in a given city.

2. Customs data: This file is produced by the customs office, and compiles the imported and exported values and quantities for each firm-destinationeight-digit product category combination. This file covers only trade in goods and therefore covers primarily manufacturing firms but also include retail and wholesale sectors as well as the service sector more generally. The data is subject to some declaration thresholds which varies depending on whether the trade is extra or within EU. For imports from outside the EU, reporting is required from each firm and flow if the imported value exceeds 1,000 Euros (this threshold was lifted in 2010 but does not vary over the sample period). For imports within the EU, there exists several threshold regarding import flows. Import flows have to be reported as long as the firm's annual trade value exceeds 100,000 Euros. There are only minor variation in the declaration thresholds of over the periods (see row 3 for imports of Table 2 in Bergounhon et al., 2018). ${ }^{31}$

3. BRN: Income and balance sheet: This file is produced by the French statistical institute (INSEE) on the basis of corporate income tax returns for firms with revenue above than $763 \mathrm{~K}$ euros. This dataset has been widely used in the trade literature (see e.g. Mayer et al., 2014). This information at the firmlevel is taken from the official form is CERFA 2050-9 which is the French equivalent to the IRS Form 1120 (Corporate Income Tax Return).

\footnotetext{
${ }^{31}$ The most significant shift is an increase in the threshold in 2001 (from 40k to 100k euros). If anything, this change should play against us finding an effect.
} 
4. Local exchange gepographical coverage data: INSEE and the regulatory agency (ARCEP) produced a file approximating the geographical coverage of each LE in terms of census blocks (IRIS in France, standing for "Ilôts regroupés pour l'information statistique").

5. Local exchange expansion date: This information was hand-collected from a website documenting the current and past quality of internet connection at the local level. It contains the exact date for each LE of the update to DSL technology. We were able to check with economists at Orange that our dates matched exactly their data for the year within the sample (1999-2007). 


\section{B.2 List of variables}

1. Value of import: This variable is constructed from the custom file matched with the establishment-level employment data. It is equal to the sum of the values of the imported goods over a given year for all firms located in a given city.

2. Number of flows: This variable is constructed from the custom file matched with the establishment-level employment data. It is defined as sum of the number of importing flows good over a given year for all firms located in a given city. An importing flow is defined as the finest level of observation available in the customs data which corresponds to a unique firm $\times$ product (HS-6) $\times$ sourcing country combination.

3. Average value per flow: This variable is defined as: Average value per flow $=$ $\frac{\text { Value of import }}{\text { Number of flows }}$

4. Density: This variable is defined as: Density $=\frac{\text { Population census } 1999}{\text { City Area }}$. The population variable is taken from the 1999 Census, the last exhaustive census available in France, which also matches the year of the very beginning of the broadband expansion.

5. Number of fiscal households and average fiscal income: source Fichier de l'impôt sur le revenu des communes (IRCOM)

6. Employment shares: Number of employees per sector, aggregated from DADS establishment data.

7. Sales: Sales are documented in the BRN files at the firm-level. This is not inclusive of VAT.

8. Value added: Value-added is documented in the BRN at the firm-level. It is inclusive of taxes on production that are deductible with respect to the corporate income tax. 


\section{Online Appendix}

\section{OA.1 Additional empirical material}

\section{Permutation-based inference}

Figure OA.1: Distribution of Placebo Estimates: Log Imports, $\beta_{4}$

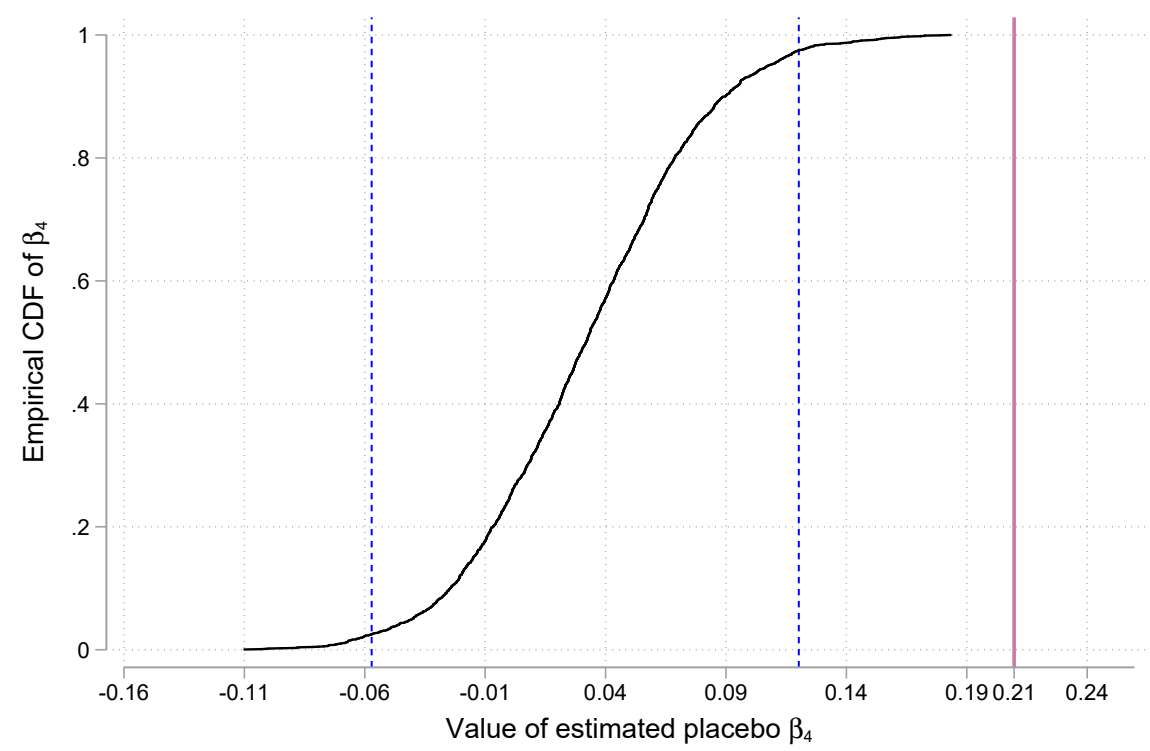

NOTES: This figure plots the empirical cumulative distribution function of placebo estimated effects broadband on log imports, where date of broadband expansion is randomly reallocated across cities within a département (unit of cluster).

Draws are with replacement and may include the correct date of treatment. The CDF is constructed from 1000 estimates of $\beta_{4}$ using the specification in equation (2) without observable controls. The solid line (in red) corresponds to

the actual estimate of the matching specification. It lies outside of the $95 \%$ confidence interval that is delineated by the dash lines (in blue). 
Figure OA.2: The progressive roll-out of the DSL technology in Occitanie $-\widetilde{Z}$

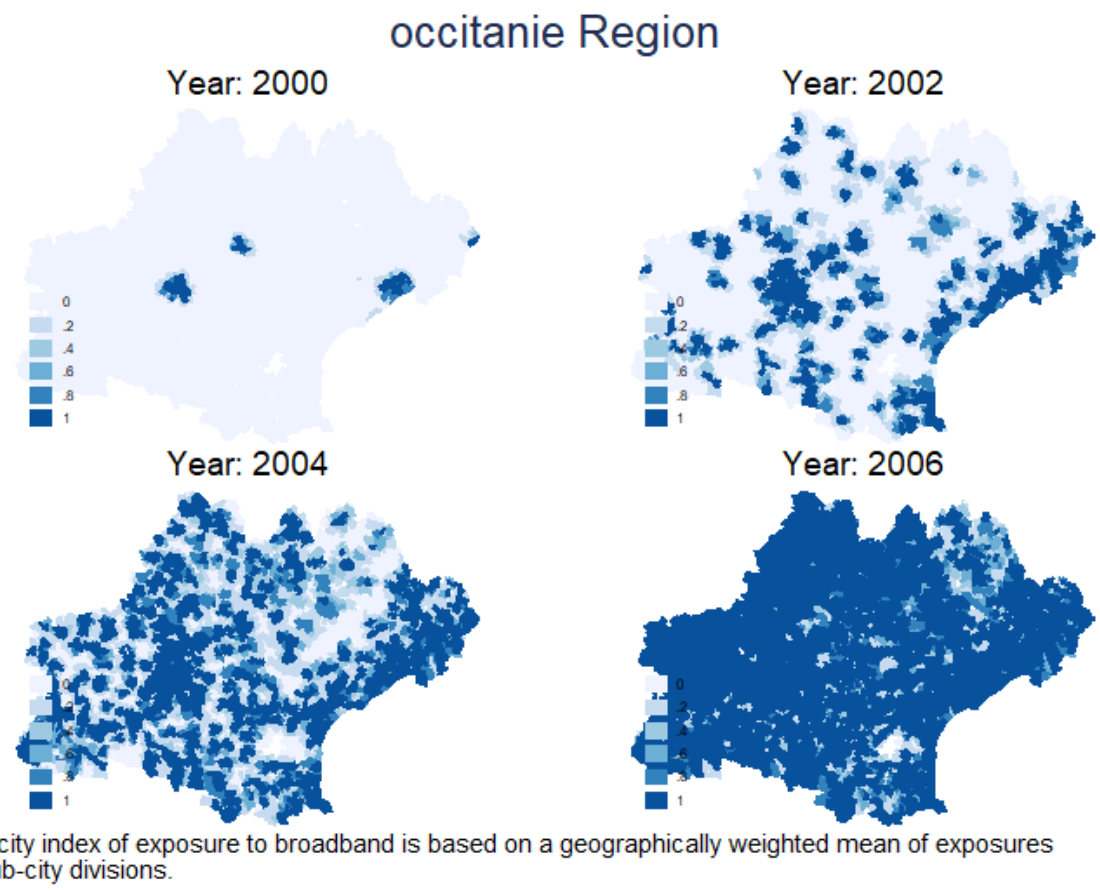

NOTES: This figure presents the geographical distribution of the continuous measure of local broadband availability (variable $\widetilde{Z}$ ) as defined in Equation (1).

Figure OA.3: Intermediate inputs over-sales-ratio

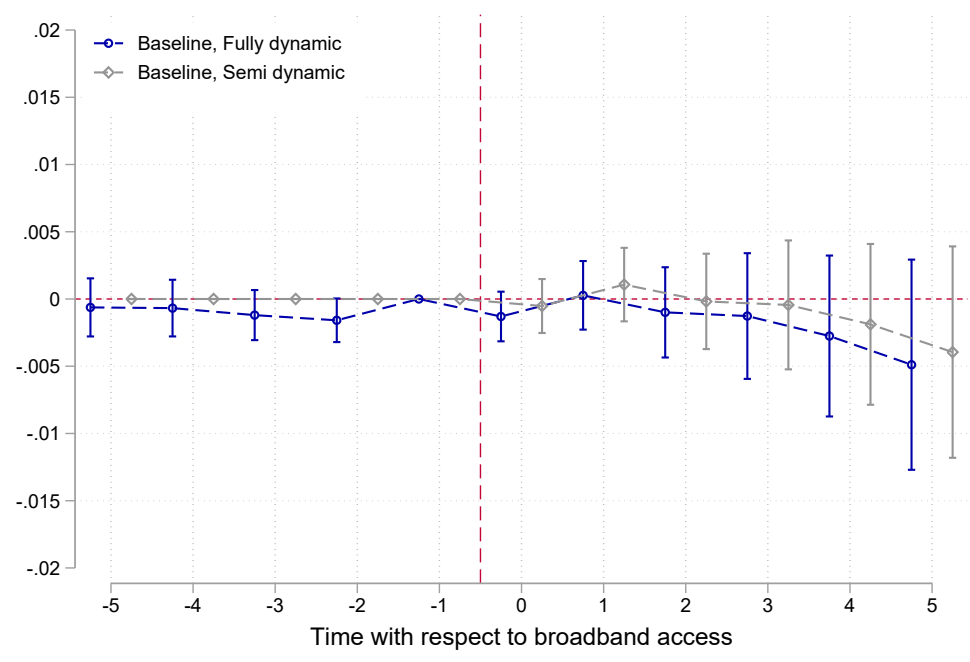




\section{OA.2 Conceptual framework: a simple example}

In firm-level importing models, the choice of the optimal set of sourcing problem is complex as, unlike for exporting problems, the choice of individual sourcing countries are interdependent as they interact through the cost function (Antras et al., 2017). The approach developed in Section 7, inspired by Blaum et al. (2018), allows us to quantify the consumer welfare effect of broadband internet in a firmlevel importing model without having to fully characterize the importing environment and solve for the optimal sourcing strategy.

In this appendix section, we illustrate the sufficiency result presented in 7.2, within a very simple but fully specified model. When not otherwise specified, the notation follows that of Section 7.

Production function follows a Cobb-Douglas:

$$
Y=A \times L^{\gamma} X^{1-\gamma}
$$

The cost minimization program writes as:

$$
\min w L+P X \text { s.t. } Y=1
$$

The resulting unit cost is:

$$
u=A^{-1} w^{\gamma} P^{1-\gamma} \times \gamma^{-\gamma}(1-\gamma)^{-(1-\gamma)}
$$

Here $X$ is aggregation from several types of goods in a CES fashion:

$$
X=\left(\sum_{c \in \Omega} \alpha_{c} D_{c}^{\frac{\varepsilon-1}{\varepsilon}}\right)^{\frac{\varepsilon}{\varepsilon-1}}
$$

where $D_{c}$ denotes the quantity of input $c$. The price of input $c$ writes as $p_{c}$. Given cost minimization and the CES production function, we have the following results: 


$$
\min \sum_{c \in \Omega} p_{c} D_{c} \text { s.t. } X=1
$$

FOC: $p_{c}=\lambda \alpha_{c} D_{c}^{-\frac{1}{\varepsilon}}$

$$
\begin{aligned}
& \sum_{c \in \Omega} D_{c} p_{c}=\lambda \sum_{c \in \Omega} \alpha_{c} D_{c}^{\frac{\varepsilon-1}{\varepsilon}} \times X^{\frac{1}{\varepsilon}}=\lambda X \\
& D_{c} p_{c}=\left(\sum_{c \in \Omega} D_{c} p_{c}\right)^{\varepsilon} \alpha_{c}^{\varepsilon} p_{c}^{1-\varepsilon} \Leftrightarrow \sum_{c \in \Omega} D_{c} p_{c}=\left(\sum_{c \in \Omega} \alpha_{c}^{\varepsilon} p_{c}^{1-\varepsilon}\right)^{\frac{1}{1-\varepsilon}}=: P
\end{aligned}
$$

Next, we consider the case of two inputs: one domestic (1) and one foreign (2). In that context, cost share of input 1 writes as:

$$
s_{1}:=\frac{D_{1} p_{1}}{D_{1} p_{1}+D_{2} p_{2}}=\frac{p_{1}^{1-\varepsilon} P^{\varepsilon} \alpha_{1}^{\varepsilon}}{P}=p_{1}^{1-\varepsilon} P^{\varepsilon-1} \alpha_{1}^{\varepsilon}
$$

Now, we consider $D_{2}$. The foreign goods is itself a CES aggregation of several national origins following an Armington-type of model:

$$
D_{2}=\left(\sum_{v \in \Theta} h_{v}^{\frac{\eta-1}{\eta}}\right)^{\frac{\eta}{\eta-1}}
$$

Unit cost will depends on variable cost $r_{v}$ plus fixed cost $f$ per destination $v$ with convex cost in the number of destination $|\Theta|(\lambda \geq 1)$ :

$$
u_{2}=\sum_{v} r_{v} h_{v}+|\Theta|^{\lambda} f
$$

Variable cost component:

$$
p_{2}(\Theta)=\left(\sum_{v \in \Theta} r_{v}^{1-\eta}\right)^{\frac{1}{1-\eta}}=|\Theta|^{\frac{1}{1-\eta}} \times r
$$

Now, the firm chooses $\Theta$ (we assume continuum of countries):

$$
u_{2}=|\Theta|^{\frac{1}{1-\eta}} \times r+|\Theta|^{\lambda} f
$$


The first order condition writes as:

$$
\begin{array}{r}
\quad \frac{r}{1-\eta}|\Theta|^{\frac{\eta}{1-\eta}}+\lambda|\Theta|^{\lambda-1} f=0 \\
\Leftrightarrow|\Theta|=\left(\frac{\lambda(\eta-1) f}{r}\right)^{\frac{1-\eta}{1-\lambda(1-\eta)}}
\end{array}
$$

We consider the case where $\lambda=1$. The unit cost of for the foreign inputs writes as:

$$
u_{2}=\left(f^{\frac{1}{\eta}} r^{\frac{\eta-1}{\eta}}\right) \underbrace{\left((\eta-1)^{\frac{1}{\eta}}+(\eta-1)^{\frac{1-\eta}{\eta}}\right)}_{\equiv B}=\frac{\eta}{\eta-1} \times f^{\frac{1}{\eta}} r^{\frac{\eta-1}{\eta}}(\eta-1)^{\frac{1}{\eta}}
$$

Consequently, the unit cost of the intermediate goods writes as:

$$
\begin{aligned}
P & =\left(\alpha_{1}^{\varepsilon} p_{1}^{1-\varepsilon}+\left(1-\alpha_{1}\right)^{\varepsilon} u_{2}^{1-\varepsilon}\right)^{\frac{1}{1-\varepsilon}} \\
& =\left(\alpha_{1}^{\varepsilon} p_{1}^{1-\varepsilon}+\left(1-\alpha_{1}\right)^{\varepsilon}\left(\left(f^{\frac{1}{\eta}} r^{\frac{\eta-1}{\eta}}\right) B\right)^{1-\varepsilon}\right)^{\frac{1}{1-\varepsilon}} \\
& =\left(\alpha_{1}^{\varepsilon} p_{1}^{1-\varepsilon}+\left(1-\alpha_{1}\right)^{\varepsilon}\left(\left(f^{\frac{1-\varepsilon}{\eta}} r^{\frac{(1-\varepsilon)(\eta-1)}{\eta}}\right) B^{1-\varepsilon}\right)\right)^{\frac{1}{1-\varepsilon}}
\end{aligned}
$$

We can then derive the fully specified overall unit cost as a function of fixed cost $f$ and variable cost $r$ of importing:

$$
u=w^{\gamma}\left(\alpha_{1}^{\varepsilon} p_{1}^{1-\varepsilon}+\left(1-\alpha_{1}\right)^{\varepsilon}\left(\left(f^{\frac{1-\varepsilon}{\eta}} r^{\frac{(1-\varepsilon)(\eta-1)}{\eta}}\right) B^{1-\varepsilon}\right)\right)^{\frac{1-\gamma}{1-\varepsilon}} \times \gamma^{-\gamma}(1-\gamma)^{-(1-\gamma)}
$$

We can also express unit cost $s$ as a function of $s_{1}$ using its relationship with the price index $P$ :

$$
u=A^{-1} w^{\gamma}\left(p_{1} / \alpha_{1}\right)^{\frac{1-\gamma}{\varepsilon-1}}\left(s_{1}\right)^{\frac{1-\gamma}{\varepsilon-1}} \times \gamma^{-\gamma}(1-\gamma)^{-(1-\gamma)}
$$

In that setting the sufficiency result states that any effect of a variation in $f, r$ on the unit cost $s$ is operating through $s_{1}$. Therefore, the effect of broadband internet on the unit cost through either changes in fixed cost $f$ or variable cost $r$ of imports is fully summarized by its effect on $s_{1}: \frac{d \ln s_{1}}{d B I} \times \frac{1-\gamma}{1-\varepsilon}$. 